\title{
Bankruptcy Regimes and Gambling on Resurrection
}

\author{
Ondřej Knot \\ Ondřej Vychodil
}
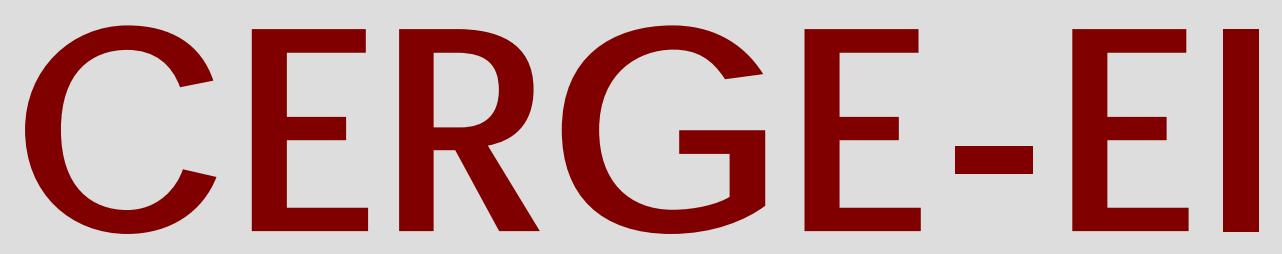

Charles University Centerfor Economic Research and Graduate Education Academy of Sciences of the Czech Republic Ec onomic Institute 
Working Paper Series

(ISSN 1211-3298)

\title{
Bankruptcy Regimes and Gambling on Resurrection
}

\author{
Ondřej Knot \\ Ondř̌ej Vychodil
}

CERGE-EI

Prague, February 2006 
ISBN 80-7343-085-1 (Univerzita Karlova v Praze, CERGE)

ISBN 80-7344-074-1 (Národohospodářský ústav AV ČR, Praha) 


\title{
Bankruptcy Regimes and Gambling on Resurrection*
}

\section{Ondř̀ej Knot ${ }^{\dagger}$ and Ondř̀ej Vychodil ${ }^{\dagger}$}

\author{
CERGE-EI**
}

February 2006

\begin{abstract}
This paper analyzes debt contracting in the presence of gambling on resurrection under different bankruptcy regimes. Ex-ante effects on investment levels, interest rates and profit, and ex-post effects on debtor's strategy choices are examined. A model of a debtor-creditor relationship is presented which shows that violation of the Absolute Priority Rule in bankruptcy (soft bankruptcy law) may partially eliminate excessive managerial risk-taking. But under law that is insufficiently soft, this moral hazard problem may be even stronger than under completely tough law. The gambling on resurrection argument for soft law is further weakened if the possibility of verifying the firm's situation by creditors is introduced.
\end{abstract}

Keywords: corporate bankruptcy, debt contracts, monitoring JEL classification: G33, K12, K39

\footnotetext{
$\dagger$

Email: ondrej.knot@cerge-ei.cz

\$Email: ondrej.vychodil@cerge-ei.cz

**A joint workplace of the Center for Economic Research and Graduate Education, Charles University, and the Economics Institute of the Academy of Sciences of the Czech Republic. Address: CERGE-EI, P.O. Box 882, Politických vězňů 7, Prague 1, 11 21, Czech Republic

* The authors would like to thank Philippe Aghion, Ronald Anderson, Douglas Baird, Lucian Bebchuk, Libor Dušek, Eugen Kováč, Gerard Roland, Robert Townsend and participants of CERGE-EI workshop in July 2005 and GDN Conference in August 2005 for helpful comments on earlier drafts of the paper. Financial support from the Global Development Network under the Regional Research Competition Grant is gratefully acknowledged. The usual disclaimer applies.
} 


\begin{abstract}
Abstrakt
Studie se zabývá uzavíráním dlužnických kontraktů za prrítomnosti hazardního boje o záchranu (angl. gambling on resurrection) v různých režimech úpadkového práva. Autoři vyvozují závěry o ex-ante dopadech na výši investic, úrokovou míru a zisk a ex-post dopadech na dlužníkovu volbu strategie. Pomocí modelu vztahu mezi dlužníkem a věřitelem ukazují, že porušení pravidla absolutní priority v úpadku (měkký úpadkový zákon) může sice částečně eliminovat př́ilišné riskování ze strany managementu dlužníka, ale za jistých okolností může naopak zhoršit problém morálního hazardu oproti situaci zcela tvrdého úpadkového zákona. Obvyklý argument pro měkký zákon postavený na problému hazardního boje o záchranu je ještě více oslaben, je-li model rozšířen o možnost verifikace stavu dlužníka ze strany věřitele.
\end{abstract}




\section{Introduction}

A question often debated among bankruptcy scholars is whether value in bankruptcy should be divided in accordance with the absolute priority rule (APR). If APR holds, it means that nothing can be paid to a class of claimholders unless the claims of all the superior classes are fully satisfied. In general, the first in the queue are secured creditors followed by other classes of creditors and the last are the equityholders. In the bankruptcy literature, ${ }^{1}$ bankruptcy laws are usually divided into tough and soft, depending on how the firm management is treated. But if management is treated favorably, i.e., the law is soft, APR violations are more likely to occur. Therefore, we may also associate soft law with the possibility of APR violations and tough law with strict observances of APR. This is the approach that we adopt in our paper.

The most discussed example of a law enabling APR violations has been Chapter 11 of the U.S. Bankruptcy Code of 1978. Although de iure APR is supposed to hold in Chapter 11, vast empirical evidence has been collected to support the hypothesis that de facto APR is violated in bankruptcy cases under Chapter $11 .^{2}$ After a bankruptcy filing, the automatic stay prevents creditors from further collection activities, the management has an exclusive position to present a plan of reorganization, and the consent of a class of creditors can be replaced under the cram down procedure by a court decision. These are just examples of rules that enable the management to enforce APR violations on the creditors. Certainly, the U.S. case is just one of many and we can observe very different bankruptcy laws around the world with different degrees of APR violation.

Facing this reality, economic (and legal) researchers have been debating over the

\footnotetext{
${ }^{1}$ For an up-to-date survey of economic literature on both personal and corporate bankruptcy, see White (2005). In our paper, we deal with corporate bankruptcy only.

${ }^{2}$ See, e.g., Franks and Torous (1989), Eberhart, Moore, and Roenfeldt (1990), LoPucki and Whitford (1990), Weiss (1990), Bebchuk and Picker (1993), Franks and Torous (1994), Betker (1995), Longhofer and Carlstrom (1995), Weiss and Wruck (1998), Carapeto (2000).
} 
optimal choice of a bankruptcy regime. There are several arguments in favor of soft law and several other arguments in favor of tough law - both from the viewpoint of ex-post efficiency and from that of ex-ante efficiency. ${ }^{3}$ In line with the claim of Hart (2000) that there is no "one size fits all" solution in bankruptcy legislation, one may say that each of these pros and cons of APR is of different relevance and strength in different countries. ${ }^{4}$

One of the ex-ante efficiency argument for soft law has been the gambling on resurrection hypothesis, which states that under APR, debtors tend toward excessive risk-taking and delaying bankruptcy filing once they privately observe that they are on the verge of bankruptcy. ${ }^{5}$ Violation of APR is believed to suppress this type of moral hazard problem as it allows the payoff of shareholders, in whose interest the management acts, to be positive even if the value of the firm is lower than the sum of all creditors' claims.

Gertner and Scharfstein (1991) point out two inefficiencies (of opposite direction) arising in the situation of financial distress under tough law. On the one hand, firms in financial distress have difficulties to issue new debt or equity, which produces underinvestment. On the other hand, shareholders get much of the upside benefit but bear little of the downside cost, which makes them overinvest and take too much risk. They show that both problems remain even if renegotiation becomes possible and the choice among laws depends on the composite result of the two opposing effects on investment.

\footnotetext{
${ }^{3}$ For a summary of some pros and cons of soft and tough bankruptcy laws, see Knot and Vychodil (2005).

${ }^{4}$ Some authors explicitly studied various country-related specific factors that should be taken into account when designing an optimal bankruptcy law. For instance, Baird and Rasmussen (2002b) and Baird and Rasmussen (2003) stress the importance of capital structure and the functioning of asset markets, Berkovitch and Israel (1998) emphasize information structure, while Lambert-Mogiliansky, Sonin, and Zhuravskaya (2003) and Biais and Recasens (2002) study the effects of corruption among judges.

${ }^{5}$ In the literature on managerial incentives, also terms "go for broke", "heads I win, tails I break even", or "fourth-quarter football" have been used interchangeably. See, e.g., Hart (2000) and Akerlof and Romer (1994).
} 
Further they argue that a reorganization law (i.e., soft law) increases investment in financial distress. Whether this is efficient then depends on whether tough law implies over- or underinvestment.

White (1998) claims that if bankruptcy means liquidation, instead of reorganization, managers tend toward risk-taking and over-continuation when problems appear. Schwartz (2002) argues that soft law mitigates the problem of avoiding bankruptcy but worsens the firm's incentives to invest. Thus, he examines the ex-ante trade-off between encouraging the firm to exert optimal effort and inducing the firm to enter bankruptcy if its project fails.

The problem of excessive continuation of equity-holders is also analyzed in Decamps and Faure-Grimaud (2002) who use the compound exchange option approach to characterize the agency cost of debt and their evolution over time. They do not, however, focus on the effects of different legal and institutional environment on these agency costs, the question we deal with in this paper.

All in all, within the literature on optimal bankruptcy law design, a tendency to gamble on resurrection has always been considered as a problem under tough law, and soft law was believed to mitigate it. In our paper, we inspect this argument and argue that it is not generally valid and should thus be used with caution.

There are several papers similar to our paper, Bebchuk (2001) probably being the most closely related. In his model, the APR violations increase the distortions of management's decision-making in favor of risky projects. In our model, too, we observe this effect under certain circumstances, but we find that soft law can eliminate these distortions under different circumstances. The difference between our model and Bebchuk's comes from the fact that Bebchuk assumes the project characteristics are given ex ante and are private information of the firm. In Bebchuk's model, once the project is started, there are no more decisions concerning its characteristics. On the 
other hand, we assume that the project's characteristics are common knowledge at the time when the project is financed. Only after that, the debtor privately learns information about how the project's chances to succeed changed and may choose a risky or a safe strategy.

Another related paper is Bester (1994). In Bester's model, the low state automatically implies default, while in the high state the debtor can either repay or default strategically. Thus the high-type debtor might pretend to be low-type and the creditor cannot distinguish between financial and strategic default. In our model, instead, we focus on the situation of the low-type pretending to be the high-type and of the creditor's lowered ability to distinguish between success-driven continuation and "cooking of the books."

Finally, in the model of Povel (1999), the debtor also receives a private signal on the project's type, unobservable by creditors, and decides either to file for bankruptcy or continue running the firm. Nonetheless, in Povel's model the debtor, in addition, chooses her effort level between the initial financing period and receiving the signal. The main idea of this model lies in the trade-off between incentives to invest effort and incentives to reveal private information about the project's type. Soft bankruptcy law worsens the former while improving the latter. In our model, we assume away the effort choice and show that even the pure effect of the law's softness on incentives to reveal true information is twofold. Under some circumstances, softening bankruptcy law strengthens the debtor's motives for gambling on resurrection and misreporting.

Obviously, the above-discussed excessive risk-taking and bankruptcy postponing tendency of the managers in the bad state of the world inevitably results in a tendency of the management to misreport the state of the world to creditors. Recently, misreporting in relation to bankruptcy has been explicitly dealt with by Baird and Rasmussen (2002a) and Baird (2003) using the case of Enron's failure and by Bar-Gil 
and Bebchuk (2003) using a theoretical framework.

Baird and Rasmussen (2002a) describe the situation before the bankruptcy of Enron as one in which Enron was able to cook its books and persuade investors of the soundness of its business strategy. Baird (2003) then describes how the managers of Enron actually managed to devise complicated transactions whose only goal was to make Enron's economic situation appear better to its creditors and business partners than it was in reality. At a certain point in time the managers had to make a decision whether to reveal problems and adopt a more conservative strategy or whether to conceal them and continue with the aggressive strategy, even though it was likely to fail. They chose the latter strategy, since betting on some future fortune might have kept them their jobs and their reputation as innovative and shrewd managers.

Bar-Gil and Bebchuk (2003) theoretically study the causes and consequences of corporate misreporting. In their model, misreporting enables managers to maintain higher share prices, which is useful when an interesting take-over possibility emerges. If the company can pay for the take-over with its own shares, higher share prices make the take-over cheaper. In their model, the misreporting opportunities are endogenous and depend on the (costly) actions taken by the firm's management before it becomes clear whether there are reasons for misreporting or not. The distortions due to misreporting consist of too much equity being issued by firms that engage in misreporting and too few by those that do not.

In this paper, we analyze contracting and monitoring in the presence of gambling on resurrection and misreporting under different bankruptcy regimes. We present a model of incomplete contracting which shows that a non-zero degree of softness of bankruptcy law (violation of APR), indeed, may partially eliminate managerial excessive risktaking just before bankruptcy and misreporting in order to delay bankruptcy. But under a law that is insufficiently soft, this moral hazard problem may be even stronger 
than under completely tough law. In addition, as firms (and their projects) differ in their characteristics, the optimal degree of softness varies from case to case. Thus if the degree of softness is given exogenously by bankruptcy law, rather than determined endogenously by the contract, the moral hazard problem becomes eliminated in some projects but aggravated in others. The gambling on resurrection argument for soft law is further weakened if a possibility for creditors to verify the firm's situation is introduced.

The model we present in this paper is, we believe, both realistic and tractable. In general, it draws the connection between financial contracting and bankruptcy law. More specifically, it allows - among others - for inspecting the links between the bankruptcy law design, credit rationing, company's misreporting, cost of monitoring, profitability of projects, and size of firms. An important part of the paper are simulations showing, for each of the bankruptcy regimes, the sensitivity of the individual variables to parameter changes.

The paper is structured as follows. The following section provides the setup of the model and defines contracts and strategies. Section three analyzes the benchmark situation of the first best solution. Further, three cases (sections four through six) of a decentralized market solution are inspected and compared to the first best. The fourth and fifth sections analyze the socially suboptimal results stemming from the problem of the debtor's misreporting when APR does and does not hold, respectively. Section six introduces the possibility for the creditor to verify, with a certain cost, the debtor's report. The seventh section considers what happens when we allow the parties to renegotiate the contract in period 1. Section eight concludes. 


\section{The Model}

\subsection{Setup}

We study the relationship between a firm and a bank. Decisions on behalf of the firm are made by its owner/manager, whom we denote interchangeably as owner or debtor hereafter. The firm has an opportunity to undertake a profitable project and needs financing from the bank in order to do so. We assume that bank credit is the only source of financing for the firm. ${ }^{6}$ The initial investment in the project is determined by the parties depending on the model parameters. During the life of the project the owner receives private information about the probability of the project's success. The information may be either good or bad. Given the investment was undertaken at the socially optimal level, it is optimal to continue the project if the information is good (the probability of success is high), and quit the project if the information is bad (the probability of success is low). The incentives of the owner, however, may be to continue the project even if the information is bad.

The project, if successful, can bring $\beta(K)$ where $K$ is a non-negative initial investment. We assume a particular form of $\beta(K)$, namely $\beta(K)=B \ln (K+1)$ where $B>0$. Note that $\beta(0)=0, \beta^{\prime}(K)>0$, and $\beta^{\prime \prime}(K)<0$. The whole investment $\mathrm{K}$ is financed by debt and can be set by a credit contract at any non-negative level. In exchange for the provided financing, the bank is promised to obtain $(1+r) K$ at the end of the game, unless the firm ends up in bankruptcy. We assume the risk-free interest rate is zero. The credit market is competitive which means that, in equilibrium, the bank's expected profit will be zero and the owner of the firm will capture all the surplus from the relationship, which also means that the owner's expected profit will be a perfect measure of the social gain from the project.

\footnotetext{
${ }^{6}$ This assumption is usual in existing models on ex-ante effects of bankruptcy law and does not limit the validity of the model's implications.
} 
The relationship extends over three periods. In period 0 a credit contract is signed and investment is realized. The contract specifies the principal $K$ (which is also the investment level), the interest rate $r$ and the strategy to be undertaken in period 1 . In period 1 the owner receives private information about the state of the world, either truthfully or untruthfully reveals it to the creditor and decides about further strategy - either continue running the project (strategy $S_{C}$ ) or quit the project (strategy $S_{Q}$ ). In the default version of the model, we assume that the creditor cannot verify the information provided by the owner. ${ }^{7}$ In period 2 outcomes are realized and returns divided according to the contract and, in the case of bankruptcy, according to the bankruptcy law.

There may be two states of the world in period 1 , the good state $(H)$ and the bad state $(L)$, with probabilities $p$ and $(1-p)$, respectively, where $0<p<1$. If the owner decides to quit the project (strategy $S_{Q}$ ), a recovery value $\gamma K$, where $0<\gamma<1$, is obtained with certainty - no matter whether the state of the world is $H$ or $L$. What makes the situations of $H$ and $L$ different are the payoffs from the project's continuation (strategy $S_{C}$ ). If the owner opts for strategy $S_{C}$ in state $H$, the project continues and yields a good outcome, $B \ln (K+1)$, with certainty.

However, in state $L$, strategy $S_{C}$ results in a good outcome, $B \ln (K+1)$, only with probability $\pi$, and in a bad outcome, 0 , with probability $1-\pi$, where $0<\pi<$ 1. It is clear that for a project that had been financed in period 0 , we must have $B \ln (K+1)>\gamma K$, otherwise the project would have not been undertaken from the very beginning. ${ }^{8}$ Therefore, if the owner observes that the state of the world is $H$, she continues the project for sure. The only decision node regarding the choice between strategy $S_{C}$ and strategy $S_{Q}$ is thus in state $L$.

\footnotetext{
${ }^{7}$ This assumption will be relaxed later in section 6 .

${ }^{8}$ Clearly, a necessary condition for the firm to undertake the project in period 0 is $B \ln (K+1) \geq$ $(1+r) K$. As $r \geq 0$ and $0<\gamma<1$, this implies $B \ln (K+1)>\gamma K$.
} 
The firm value before the start of the project is $V>0$. This can be thought of as the value of the assets the firm possesses and that may serve as collateral. To focus on the gambling-for-resurrection problem, we assume that all the revenues from the project, once they are realized, are verifiable by court and the debtor cannot run away with them. ${ }^{9}$

The assumptions about the parameters made in this section are technically stated in Assumption 1 in Appendix A.4.

Throughout the paper, besides providing analytic derivations of optimal contracts under different legal and institutional setups, we illustrate these contracts by simulations on a numerical example with parameters given as $p=0.6, \pi=0.2, \gamma=0.65$, and $V=2$, unless stated otherwise. Graphical representations of these simulations are provided in Appendix A.2.

\subsection{Contracts and Strategies}

Both the owner and the bank are risk-neutral agents who maximize their expected profits. Strategy $S_{i} \in\left\{S_{C}, S_{Q}\right\}$ is the owner's decision whether to continue $\left(S_{C}\right)$ or quit $\left(S_{Q}\right)$ the project in state $L$ (the only decision node after the project has been started). A contract is a triple $\left(K, r, S_{i}\right) \in \Re_{+}^{2} \times\left\{S_{C}, S_{Q}\right\}$. The bank lends to the firm $K$ in period 0 , and the owner promises on behalf of the firm to repay $(1+r) K$ in period 2. The owner also commits to follow strategy $S_{i}$ in period 1 if state $L$ occurs. Denote the owner's expected profit and the bank's expected profits in period $t$ as $F_{t}\left(K, r, S_{i}\right)$ and $G_{t}\left(K, r, S_{i}\right)$, respectively, where $t=0,1$.

A contract $\left(K, r, S_{i}\right)$ is incentive compatible if in period 1 , when the owner decides whether to quit or continue, $F_{1}\left(K, r, S_{i}\right) \geq F_{1}\left(K, r, S_{j}\right), i \neq j$. A contract is feasible if it is incentive compatible and $G_{0}\left(K, r, S_{i}\right) \geq 0$. The debtor's maximization problem

\footnotetext{
${ }^{9}$ Assuming that the project proceeds accrue to the debtor herself in the first place and that she can seize them would lead to the possibility of strategic default, as in Hart and Moore (1998).
} 
has, thus, the following form:

$$
\begin{aligned}
& \max _{\left(K, r, S_{i}\right) \in \Re_{+}^{2} \times\left\{S_{C}, S_{Q}\right\}} F_{0}\left(K, r, S_{i}\right) \\
& \text { s.t. } \\
& F_{1}\left(K, r, S_{i}\right) \geq F_{1}\left(K, r, S_{j}\right), \quad i \neq j, \\
& G_{0}\left(K, r, S_{i}\right) \geq 0 .
\end{aligned}
$$

In period 1 the owner privately learns the state of the world, reports it to the creditor, and chooses between strategies $S_{C}$ and $S_{Q}$. The creditor cannot observe the state of the world, he only observes the choice of strategy. ${ }^{10}$ If the period 1 state of the world is $H$, there is no moral hazard as continuation $\left(S_{C}\right)$ is the optimal strategy for both the debtor and the creditor. Thus if state $H$ occurs, the project continues smoothly to period 2 . If the period 1 state is $L$ and the contract requires the owner to follow $S_{Q}$, then, for certain levels of $K$ and $r$, the owner has an incentive to misreport (i.e., report state $H$ ) and to follow $S_{C}$.

This is where our model differs from the previous literature, which usually defines a good state as a realization of high cash flows which the debtor can divert instead of paying them to the lender. ${ }^{11}$ There the principal-agent problem is particularly salient in the good state. On the other hand, our model is built on the assumption that the cash flows that only accrue in period 2 are observable and verifiable. The distinction between a good and a bad state takes place before the cash flow realization. The good state is associated with a high probability (in the model, for simplicity, we assume

\footnotetext{
${ }^{10}$ Formally, the assumption that the report will be made by the debtor seems redundant, but it will become utilized later in the treatment with verification. In fact, here we assume that the debtor can report untruthfully without any risk of detection because the cost of verification is infinitely high.

${ }^{11}$ See, e.g., Bester (1994), Berglof and von Thadden (1994), Bolton and Scharfstein (1996), Hart and Moore (1998), and Berglof, Roland, and von Thadden (2003).
} 
certainty) of success (i.e., high cash flows) whereas the bad state with a low probability of success. In the good state, the principal-agent problem is not an issue. On the other hand, it becomes an issue in the bad state when the owner has an incentive to gamble on resurrection.

We will analyze the contracts and strategies within the model in the following way. As a benchmark case, we first describe the first best solution to the problem which would be achieved by a social planner who maximizes the social surplus $H_{0}\left(K, r, S_{i}\right)=$ $F_{0}\left(K, r, S_{i}\right)+G_{0}\left(K, r, S_{i}\right)$. Then we solve for the optimal contract under tough law. Then we analyze whether soft law may outperform tough law. Finally, we introduce a possibility of verification to the tough law setup as an alternative solution. In each case, we solve the problem by backward induction. First, we examine the behavior of the debtor and the creditor in period 1 , given $K$ and $r$, and second, we examine the determination of optimal $K$ and $r$ in period 0 .

\section{Social Planner}

In this part we examine how the problem described above would be solved by a social planner who does not face the incentive compatibility constraints present in the decentralized setup. The criterion for the efficiency of bankruptcy law that we use in this paper is that the rules of a bankruptcy law are optimal if the ex-post distribution provides incentives that lead to optimal ex-ante actions. This is common to theoretical models on ex-ante incentives of bankruptcy laws. ${ }^{12}$ Out of these, the structure of our model is most similar to those of Bester (1994), Bebchuk (2001), and Povel (1999).

For a social planner maximizing overall social welfare, the interest rate $r$ does not

\footnotetext{
${ }^{12}$ These include Adler (1992), Bebchuk (1991), Bebchuk (2001), Berglof, Roland, and von Thadden (2003), Berkovitch, Israel, and Zender (1998), Bester (1994), Bolton and Scharfstein (1996), Daigle and Maloney (1990), Gertner and Picker (1992), Harris and Raviv (1992), Picker (1992), and Povel (1999).
} 
matter because it represents a mere redistribution from the owner to the bank. The social planner would maximize the overall surplus which could be done in the following way. First, take the strategy $S_{i}$ as given and find optimal $K_{i}^{F B}$. Second, compare the overall expected payoffs $H_{0}\left(K_{i}^{F B}, S_{i}\right), i=Q, C$ and select such a combination $\left(K_{i}^{F B}, S_{i}\right)$ for which the overall payoff is higher.

The corresponding maximization problems, whose results are to be compared, are:

$$
\max _{K \geq 0} H_{0}\left(K, S_{C}\right)=V+[p+(1-p) \pi] B \ln (K+1)-K
$$

for $S_{C}$ (continuing the project) in state $L$, and

$$
\max _{K \geq 0} H_{0}\left(K, S_{Q}\right)=V+p B \ln (K+1)+(1-p) \gamma K-K
$$

for $S_{Q}$ (quitting the project) in state $L$. The corresponding levels of $K$ are

$$
K_{C}^{F B}=[p+(1-p) \pi] B-1
$$

and

$$
K_{Q}^{F B}=\frac{p B}{1-(1-p) \gamma}-1
$$

as long as the RHS of (6) and (7) are non-negative. ${ }^{13}$ The subscripts denote the strategy chosen in period 1 . We denote $K^{F B}$ (without subscript) as the level of $K$ that corresponds to the socially efficient strategy. That is, $K^{F B}=K_{i}^{F B}$ such that $H_{0}\left(K_{i}^{F B}, S_{i}\right) \geq H_{0}\left(K_{j}^{F B}, S_{j}\right)$ for $j \neq i$.

Substituting (6) and (7) to the RHS of (4) and (5), respectively, we obtain the

\footnotetext{
${ }^{13}$ This is technically guaranteed by Assumptions 3 and 4 in Appendix A.4.
} 
maximized social surplus, given the strategy choice:

$$
\begin{aligned}
& H_{0}\left(K_{C}^{F B}, S_{C}\right)=V+1-[p+(1-p) \pi] B\{1-\ln [p+(1-p) \pi] B\} \\
& H_{0}\left(K_{Q}^{F B}, S_{Q}\right)=V+[1-(1-p) \gamma]-p B\left\{1-\ln \frac{p B}{1-(1-p) \gamma}\right\} .
\end{aligned}
$$

As is clear from the motivation of our paper, we are interested in situations where, once state $L$ occurs, $S_{Q}$ is socially optimal. This is where the moral hazard problem in the form of gambling on resurrection is most salient. Thus in the remainder of the paper we are interested only in cases when $\left(K_{Q}^{F B}, S_{Q}\right)$ is socially preferred to $\left(K_{C}^{F B}, S_{C}\right)$, i.e., $K^{F B}=K_{Q}^{F B}$. Also, we assume $K_{Q}^{F B} \geq K_{C}^{F B}>0$. In Appendix A.4, these assumptions are expressed in terms of the exogenous parameters as Assumptions 2 through 4. Thus, as $S_{Q}$ is socially optimal and $K_{Q}^{F B} \geq K_{C}^{F B}>0$, the first best solution is given by the following proposition.

Proposition 1. The first best solution for $K$ and $S_{i}$ is

$$
\begin{aligned}
& K^{F B}=K_{Q}^{F B}=\frac{p B}{1-(1-p) \gamma}-1, \\
& S_{i}^{F B}=S_{Q} .
\end{aligned}
$$

Obviously, $K^{F B}$ defined in Proposition 1 is increasing in all $B, p$, and $\gamma$ and independent of the firm's assets, $V$, as these are exogenous and assumed to be saved in either state of the world. In turn, the social surplus, $H_{0}\left(K^{F B}, S_{Q}\right)$ given by equation (9), is also increasing in $B, p$, and $\gamma$. In addition, it increases one-to-one with $V$. Both $K^{F B}$ and $H_{0}\left(K^{F B}, S_{Q}\right)$ are independent of $\pi$ as the first-best strategy is $S_{Q}$ which ensures that the gamble on resurrection, whose riskiness is given by $\pi$, is avoided.

These results are graphically simulated in Appendix A.2.1. Figures 4 and 5 illustrate, the dependence of the first best level of investment and the social surplus on $B$, 
respectively, holding $p$ and $\gamma$ constant at $p=0.6$ and $\gamma=0.65$.

\section{Tough Bankruptcy Law}

Consider the situation when APR holds, i.e., when the debtor's payoff in period 2 is zero whenever the creditor is not paid in full. The decision of the debtor which strategy to choose in period 1 depends only on $K$ and $r$ chosen in period 0 . For the extensive form representation of the game under tough bankruptcy law, see Figure 1 in Appendix A.1.

There are two possible situations. First, $K$ may be such that the owner will prefer $S_{Q}$ in state $L$. Then the debt is risk-less and $r=0$. The reason why the debt is riskless is that for such a contract to be feasible the owner must obtain some payoff after quitting the project, which also means that the bank will be repaid in full. Second, $K$ may be such that the owner will prefer $S_{C}$ in state $L$, the debt will be risky and $r>0$. The owner will choose a contract from the set of feasible contracts that leads to the highest expected profit.

\subsection{Quitting the Project in State $L$}

In this subsection we analyze contracts such that the owner will prefer $S_{Q}$ in state $L$. As mentioned above, the bank will always be repaid in full which implies $r=0$. We, therefore, need to solve only for optimal $K$. The problem is that the higher $K$, the more appealing is $S_{C}$ for the owner. In order to induce the owner to select $S_{Q}, K$ must not be too high. In addition, with increasing $B$ and $\pi$, the maximum $K$ compatible with $S_{Q}$ decreases. This is shown in Figure 6 in Appendix A.2.2 for the case of $B$.

In order for the contract $\left(K, 0, S_{Q}\right)$ to be feasible, the following condition must 
hold:

$$
V+\gamma K-K \geq \pi[V+B \ln (K+1)-K]
$$

This incentive compatibility constraint implies the satisfaction of a participation constraint, which means that a participation constraint would always be slack and we do not need to account for it explicitly. ${ }^{14}$ Indeed, had the strategy to quit led to bankruptcy and thus zero profit for the owner, her commitment to quit the project in state $L$ would not be credible from the beginning because continuation would give her a positive payoff with probability $\pi$.

The debtor's maximization problem takes the following form:

$$
\max _{K \geq 0}\{V+p B \ln (K+1)+(1-p) \gamma K-K\}
$$

subject to the incentive compatibility constraint given by (11). Denote the value of $K$ that solves this optimization as $K_{Q}^{T} \cdot{ }^{15}$

If constraint (11) is not binding, then $K_{Q}^{T}=K^{F B}=K_{Q}^{F B}$, as (12) coincides, except for the constant term $V$, with the social planner's maximization problem (5). For this to be the case, the solution to the unconstrained problem (12) must satisfy constraint (11), i.e.,

$$
(\gamma+\pi-1)\left[\frac{p B}{1-(1-p) \gamma}-1\right]-\pi B \ln \left(\frac{p B}{1-(1-p) \gamma}\right)+(1-\pi) V \geq 0
$$

As long as this inequality holds, the contract under tough law implements the first best.

\footnotetext{
${ }^{14}$ The fact that inequality (11) implies full repayment for the bank with certainty stems from the following. The necessary condition for the project to be financed, $B \ln (K+1) \geq(1+r) K$, implies that the RHS of (11) is always bigger than zero, which makes the LHS positive as well. That is why the participation constraint holds and why the LHS of (11) need not have the form of $\max \{V+\gamma K-K, 0\}$.

${ }^{15}$ Hereafter, the superscript $T$ denotes optimal values under tough law regime.
} 
In the remainder of this subsection we analyze a more interesting case when constraint (11) is binding, i.e., when (13) does not hold. In this case, the first best $K$, $K^{F B}$, is too large for $S_{Q}$ to be incentive compatible. We therefore need to decrease $K$ below its first best level. If the constraint is binding, then the optimal level of $K$ can be obtained by setting this constraint equal to zero and solving for $K$. That is,

$$
(\gamma+\pi-1) K_{Q}^{T}-\pi B \ln \left(K_{Q}^{T}+1\right)+(1-\pi) V=0
$$

Although the solution cannot be obtained in the closed form, the dependence of $K_{Q}^{T}$ on the parameters of the model can be found by total differentiation of (14). First, consider the dependence on the firm value $V$ :

$$
\frac{\partial K_{Q}^{T}}{\partial V}=\frac{1-\pi}{\pi\left(\frac{B}{K_{Q}^{T}+1}-1\right)-(\gamma-1)} .
$$

The expression $\pi\left(\frac{B}{K_{Q}^{T}+1}-1\right)$ is positive. It could be equal to zero for $p=1$, had this been possible, but for all $p<1$, it becomes positive because the optimal $K_{Q}^{T}$ is never larger than for $p=1$. The term $(\gamma-1)$, to the contrary, is negative. Therefore, the denominator is positive and, as the numerator is also positive, we have $\partial K_{Q}^{T} / \partial V>0$. This is intuitive as higher firm value makes it easier for the owner to credibly commit to not follow the risky strategy.

The dependence of $K_{Q}^{T}$ on both $\pi$ and $B$ is negative:

$$
\begin{aligned}
\frac{\partial K_{Q}^{T}(\pi)}{\partial \pi} & =\frac{V+B \ln \left(K_{Q}^{T}+1\right)-K_{Q}^{T}}{(\gamma-1)-\pi\left(\frac{B}{K_{Q}^{T}+1}-1\right)}<0 \\
\frac{\partial K_{Q}^{T}(B)}{\partial B} & =\frac{\pi \ln \left(K_{Q}^{T}+1\right)}{(\gamma-1)-\pi\left(\frac{B}{K_{Q}^{T}+1}-1\right)}<0 .
\end{aligned}
$$

The negative relationship, which may seem counter-intuitive at first sight, is due to 
the fact that the higher is the upside of the project, $B$, or the probability of success in state $L, \pi$, the more difficult it is to discourage the debtor from $S_{C}$. As $K_{Q}^{T}$ decreases and $K_{Q}^{F B}$ increases in both $B$ and $\pi$, the inefficiency due to the principal-agent problem increases in $B$ and $\pi$.

$K_{Q}^{T}$ does not depend on $p$. The reason is that the only relevant relationship is between the payoffs of the individual strategies for the debtor once state $L$ occurs. The debtor needs to be motivated to prefer strategy $S_{Q}$ over strategy $S_{C}$ in state $L$, regardless with what probability the state occurs. The probability, $p$, however, affects the debtor's expected payoff in period 0 and, therefore, affects whether $K_{Q}^{T}$ is the solution to the whole problem.

To conclude this subsection, we summarize the solution for $K_{Q}^{T}$ by the following proposition.

Proposition 2. Under tough law, given strategy choice $S_{Q}$,

$$
\begin{aligned}
& K_{Q}^{T}=\left\{\begin{array}{lll}
\frac{p B}{1-(1-p) \gamma}-1 & =K^{F B} & \text { if }(13) \text { holds } \\
K_{Q}^{T} \text { given by }(14) & <K^{F B} & \text { otherwise }
\end{array}\right. \\
& r_{Q}^{T}=0 .
\end{aligned}
$$

\subsection{Continuing the Project in State $L$}

In this subsection we assume that the owner will offer a contract involving $S_{C}$. Unlike in the situation in subsection 4.1, full repayment will not be guaranteed and, hence, the interest rate $r$ will be positive to compensate the bank for the risk. Because of the credit market competitiveness and the risk-neutrality assumption, the interest rate will only ensure that the bank will just break even in expected terms and its expected profit will be zero.

Denote the optimal $K$ and $r$, given that the contract involves $S_{C}$, as $K_{C}^{T}$ and $r_{C}^{T}$. 
In order for the creditor to be willing to lend, the following participation constraint must be satisfied:

$$
[p+(1-p) \pi]\left(1+r_{C}^{T}\right) K_{C}^{T}+(1-p)(1-\pi) V-K_{C}^{T} \geq 0
$$

If the debtor follows the risky strategy $S_{C}$ in state $L$, the project succeeds with probability $\pi$. The overall probability of success is, therefore, $[p+(1-p) \pi]$. With this probability the bank is repaid in full, i.e., gets $\left(1+r_{C}^{T}\right) K_{C}^{T}$. With probability $(1-p)(1-\pi)$ the project fails and the bank gets just the value of the firm's assets, $V$.

For reasons that will be explained in more detail in subsection 4.3, we will not need the incentive compatibility constraint whenever $S_{C}$ will come into question as an optimal strategy. We therefore do not write an ICC in the following maximization problem.

$$
\begin{gathered}
\max _{K \geq 0, r \geq 0}\{[p+(1-p) \pi][V+B \ln (K+1)-(1+r) K]\} \\
\text { s.t. } \\
\text { PC: } \quad[p+(1-p) \pi](1+r) K+(1-p)(1-\pi) V-K \geq 0 .
\end{gathered}
$$

As long as the choice of $S_{C}$ over $S_{Q}$ implies that $V<[p+(1-p) \pi] B-1$, the solutions for $K$ and $r$ are as stated in the following proposition.

Proposition 3. Under tough law, given strategy choice $S_{C}$,

$$
\begin{aligned}
K_{C}^{T} & =[p+(1-p) \pi] B-1=K_{C}^{F B}<K^{F B}, \\
r_{C}^{T} & =\frac{1-[p+(1-p) \pi]}{p+(1-p) \pi}\left(1-\frac{V}{[p+(1-p) \pi] B-1}\right)>0 .
\end{aligned}
$$

The level of $K$ is the same as the socially optimal level, given that strategy $S_{C}$ is chosen in state $L$. Once the owner prefers strategy $S_{C}$ (and the bank issues a risky 
debt with a positive interest rate), the inefficiency due to the principal-agent problem between the debtor and the bank rests only in the strategy choice. Given the strategy choice, $K$ is set optimally.

\subsection{Optimal Contract under Tough Law}

In subsection 4.1 we found the decentralized solution given that the bank can believe the debtor not to gamble on resurrection. We showed that in this case there is always full repayment and, thus, the interest rate is zero. In subsection 4.2 we found the solution for the case when the debtor opts for the risky strategy which may involve a non-zero interest rate stemming from the risk of less-than-full repayment after the project failure. We now put the two cases together and derive the equilibrium amount of investment, $K^{T}$, under the tough law regime.

Ex ante the debtor decides which of the two types of contract to offer to the creditor. Thus she compares her ex-ante payoff from the contract $\left(K_{Q}^{T}, 0, S_{Q}\right)$ with that from the contract $\left(K_{C}^{T}, r_{C}^{T}, S_{C}\right)$. Here, $K_{Q}^{T}$ is determined by Proposition 2 and $K_{C}^{T}$ and $r_{C}^{T}$ are determined by Proposition 3. The owner will prefer this contract, $\left(K_{C}^{T}, r_{C}^{T}, S_{C}\right)$, to the contract involving $S_{Q},\left(K_{Q}^{T}, 0, S_{Q}\right)$, iff

$$
\begin{array}{r}
{[p+(1-p) \pi]\left[V+B \ln \left(K_{C}^{T}+1\right)-\left(1+r_{C}^{T}\right) K_{C}^{T}\right]>} \\
>V+p B \ln \left(K_{Q}^{T}+1\right)+(1-p) \gamma K_{Q}^{T}-K_{Q}^{T}
\end{array}
$$

If the owner could always commit to $S_{Q}$ in the contract, she would prefer this strategy ex ante and set $K=K_{Q}^{F B}=K^{F B}$. However, for parameter values such that (13) does not hold, the owner would violate the commitment to choose $S_{Q}$. Thus, in order to make the commitment to $S_{Q}$ incentive compatible, we need to have $K_{Q}^{T}<$ $K_{Q}^{F B}$. However, this involves a distortion and the profit is smaller than the maximum possible social gain. If this dead-weight loss becomes large enough, it is no longer 
optimal to decrease $K$ any further. At this point, giving the owner incentives to choose $S_{Q}$ becomes too costly and $S_{C}$ becomes the optimal strategy.

If the strategy to be chosen by the debtor in state $L$ is $S_{C}$, we only need to ensure that the bank's participation constraint holds. Intuitively, the incentive compatibility constraint will not be needed because the contract involving $S_{C}$ becomes optimal only when the distortion associated with satisfying the ICC for $S_{Q}$ is too large and it becomes too costly to deter the owner from the choice of risky strategy $S_{C} \cdot{ }^{16}$ This justifies the omission of the ICC from the analysis in the previous subsection.

Now, we examine how $K^{T}$ evolves with the upside of the project, $B$, holding the other parameters $-p, \pi, \gamma, V$ - constant. To ease the analysis, we denote $B_{1}$ and $B_{2}$ the threshold values of $B$ for which (13) and (21), respectively, hold with equality. Given parameters $p, \pi, \gamma, V$, the threshold $B_{1}$ is determined by

$$
(\gamma+\pi-1) K^{F B}\left(B_{1}, p, \gamma\right)-\pi B_{1} \ln \left(K^{F B}\left(B_{1}, p, \gamma\right)+1\right)+(1-\pi) V=0
$$

and sets the minimum level of $B$ for which the ICC (11) in the zero-interest-rate situation is binding. Given parameters $p, \pi, \gamma, V$, the threshold $B_{2}$ is determined by

$$
\begin{aligned}
& {[p+(1-p) \pi]\left[V+B_{2} \ln \left(K_{C}^{T}\left(B_{2}, p, \pi\right)+1\right)-\right.} \\
& \left.\quad-\left(1+r_{C}^{T}\left(B_{2}, p, \pi, V\right)\right) K_{C}^{T}\left(B_{2}, p, \pi\right)\right]= \\
& =V+p B_{2} \ln \left(K_{Q}^{T}\left(B_{2}, p, \pi, \gamma, V\right)+1\right)-[1-(1-p) \gamma] K_{Q}^{T}\left(B_{2}, p, \pi, \gamma, V\right)
\end{aligned}
$$

and represents the minimum level of $B$ for which the debtor prefers a contract involving

\footnotetext{
${ }^{16}$ Such a contract will automatically involve $r>0$ because there is a risk of less than full repayment for the bank, for which it needs to be compensated. This can be shown as follows. Suppose the owner can repay the bank in full even after the project fails and there is only $V$ left. The owner thus remains in the residual claimant position in all the situations that may occur, which rules out the gambling-on-resurrection type of moral hazard. Absent this type of moral hazard, the owner would always choose the socially optimal strategy which is $S_{Q}$.
} 
$S_{C}$ and a positive interest rate to that involving $S_{Q}$ and a zero interest rate. It can be shown (see Proof in Appendix A.4) that whenever the socially optimal strategy in state $L$ for $B=B_{1}(p, \pi, \gamma, V)$ is $S_{Q}$, then

$$
B_{1}(p, \pi, \gamma, V) \leq B_{2}(p, \pi, \gamma, V)
$$

Having defined the two thresholds and observed that $B_{1} \leq B_{2}$, we can describe the dependence of $K^{T}$ on $B .^{17}$

Proposition 4. Under tough law,

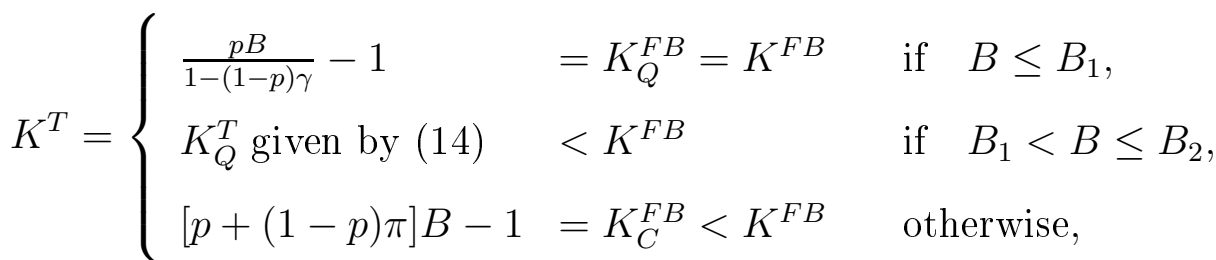

$$
\begin{aligned}
& r^{T}= \begin{cases}0 & \text { if } B \leq B_{2}, \\
\frac{1-[p+(1-p) \pi]}{p+(1-p) \pi}\left(1-\frac{V}{[p+(1-p) \pi] B-1}\right) & \text { otherwise }\end{cases} \\
& S_{i}^{T}=\left\{\begin{array}{lll}
S_{Q} & =S_{i}^{F B} & \text { if } \quad B \leq B_{2}, \\
S_{C} & \neq S_{i}^{F B} & \text { otherwise. }
\end{array}\right.
\end{aligned}
$$

For sufficiently low values of $B, K^{T}$ is the same as the first best. When $B$ reaches levels (starting at $B_{1}$ ) for which the owner would, after having chosen the first best level of $K$ in the beginning, prefer strategy $S_{C}$ in state $L, K^{T}$ must be lower than the first best level in order to make the choice of strategy $S_{Q}$ incentive compatible for the owner, i.e., to make her promise to quit in the bad state credible. Up to the level of $B=B_{2}, K$ is decreasing in $B$. For $B$ 's above $B_{2}$, the owner prefers a contract involving $S_{C}$ and a positive interest rate and the optimal $K$ jumps upward to $K_{C}^{F B}=K_{C}^{T}$. The

\footnotetext{
${ }^{17}$ Note again that we are interested only in the situations when $K_{Q}^{F B}>0$ and the socially optimal strategy is $S_{Q}$.
} 
profit maximizing investment level is, therefore, lower than the first best level which is $K^{F B}=K_{Q}^{F B}$.

The dependence of $K$ on $B$ is illustrated in Figure 7 in Appendix A.2.2. Assuming $p=0.6, \pi=0.2, \gamma=0.65$, and $V=2$, the firm is able to finance the project on the efficient scale for $B \leq B_{1}=4.56$. At $B=B_{1}, K^{T}=K^{F B}=2.70$. For values of $B>B_{1}, K^{T}$ is decreasing in $B$ to satisfy the incentive compatibility constraint (11). It reaches a minimum of 2.17 at $B_{2}=5.52$. At this point the inefficiency from further decreasing $K$ exceeds that from choosing strategy $S_{C}$, and $S_{C}$ becomes the optimal strategy for the owner. $K$ jumps up discontinuously to 3.77 . At this point, the interest rate also becomes positive, in particular, at $B=B_{2}, r=0.11$. At the level of $B_{2}$, the expected profit of the owner from both $S_{C}$ and $S_{Q}$ is the same and equal to 4.21.

Figure 8 then illustrates the owner's expected payoff in period 0 as a function of $B$. As we assume the credit market to be perfectly competitive, the owner's expected payoff represents the whole social surplus generated by the project. For $B \leq B_{1}$, the payoff is the same as the first best social gain and the debtor follows $S_{Q}$. For $B_{1}<B \leq B_{2}$, the profit falls short of the first best social gain but the debtor still follows $S_{Q}$. For $B$ 's above $B_{2}$, the debtor prefers $S_{C}$ and the profit still falls short of the first best but with $B$ increasing the gap attenuates.

One can discuss the dependence of $K^{T}$ also on other parameters. For example, the higher is the firm's value, $V$, the higher $B$ is still compatible with financing the project at the first best level. However, $V$ only affects at which level of $B$ the incentive compatibility constraint (11) starts to bind but the pattern of $K^{T}$ is then the same. Lower probability of the gamble's success, $\pi$, allows the bank to finance the project at the first best level for higher $B$ 's, but it also means lower investment and, hence, higher distortion, once the first best investment level is not possible. 


\section{$5 \quad$ Soft Bankruptcy Law}

Having analyzed the moral hazard situation in a regime of tough bankruptcy law, we now move to a regime of soft bankruptcy law which gives the owner of a bankrupt firm bargaining power that enables her to always keep a fraction of the firm value, even if the creditors are not paid in full. In other words, soft law enables violation of the absolute priority rule (APR). The APR violations come from the fact that the owner may be indispensable in order to obtain the maximum value of the firm's assets. Or she can threaten to obstruct the bankruptcy procedure to force some concessions on the creditors. The creditors may then be willing to give up a fraction of what they would be entitled to in order to assure collaboration of the management.

An often-cited example of a soft bankruptcy law is the U.S. Bankruptcy Code, especially its reorganization chapter, Chapter 11. There is substantial evidence that the APR is often violated in Chapter 11 cases. Longhofer and Carlstrom (1995), for example, survey the existing empirical literature on APR violations and find that in the sample of large corporations with publicly traded securities APR violations occur in $75 \%$ of reorganizations.

In this section, we analyze what effect the possibility of APR violation has on the ex-post strategy choice and, in turn, on the investment level and interest rate ex-ante. We model soft law by introducing a parameter $\alpha$, having $0 \leq \alpha \leq 1$, which we call the degree of softness. This parameter determines the fraction of the residual value of a bankrupt firm that is captured by the owner. Under the tough law regime we implicitly assumed $\alpha=0$. Now, we relax this assumption and examine two cases: one in which $\alpha$ is determined endogenously within the contract and the other in which $\alpha$ is given by the law. ${ }^{18}$

\footnotetext{
${ }^{18}$ For a discussion on the possibility of voluntary contracting for the violation of APR in case of bankruptcy, see Povel (1999) and Schwartz (1998).
} 
In subsection 5.1, we assume that the degree of softness, $\alpha$, can be set individually for each contract. This allows the parties to contract along another dimension, which was not possible under tough law and should, therefore, result in at least as good profit for the owner as tough law does. Assuming an endogenous determination of $\alpha$ enables us to obtain the set of admissible $\alpha$ 's (i.e., those consistent with the implementation of the first best) for each combination of parameters $\{B, p, \pi, \gamma, V\}$.

In subsection 5.2, we analyze what happens if $\alpha$ is set exogenously, a case more likely to be observed in reality. Although the parties cannot set $\alpha$ in the contract, the values of $K$ and $r$ that they specify determine both which strategy the manager will choose and whether choice of $S_{Q}$ in state $L$ implies full or partial repayment to the creditor. While the possibility to choose $\alpha$ allows for minimizing the interest rate, for $\alpha$ set exogenously, the interest rate will generally be higher.

\subsection{Endogenous Determination of $\alpha$}

Assume that the contract in period 1 specifies $\alpha$ in addition to $K, r$, and $S_{i}$. If the optimal $\alpha$ is zero, the parties agree on this in the contract and the game becomes the same as under tough law. This is the case when the inequality (13) holds for the first best value of $K$, i.e., when parameters are such that $B \leq B_{1}(p, \pi, \gamma, V)$ given by equation (22). No APR violation is needed to induce the owner to choose the optimal strategy in state $L$, the creditor is repaid in full with certainty and the optimal contract sets both $r$ and $\alpha$ to zero.

Now, we analyze the situation when $B>B_{1}(p, \pi, \gamma, V)$. Here, tough law cannot implement the first best and the question is whether contracting for $\alpha>0$ can improve the outcome. To ensure that the owner chooses $S_{Q}$ in state $L$ and that the bank is willing to provide financing at the beginning, the following incentive compatibility and 
participation constraints must both hold for $K=K^{F B}$ :

$$
\begin{gathered}
\alpha(V+\gamma K) \geq \pi[V+B \ln (K+1)-(1+r) K]+(1-\pi) \alpha V, \\
p(1+r) K+(1-p)(1-\alpha)(V+\gamma K)-K \geq 0 .
\end{gathered}
$$

The last term on the RHS of the ICC (25) captures the fact that even after the project failure, the owner is still able to keep fraction $\alpha$ of the remaining firm value. ${ }^{19}$ However, as long as the ICC holds, the RHS payoff never occurs, since the owner chooses $S_{Q}$. Further, we can be sure that whenever strategy $S_{Q}$ after state $L$ is not followed by bankruptcy at $t=2$, the optimal $\alpha$ chosen in the contract at $t=0$ is zero because it does not affect the owner's payoff. Thus, as long as optimal $\alpha$ is positive, the owner's payoff from quitting and filing for bankruptcy, $\alpha(V+\gamma K)$, exceeds that of quitting and remaining solvent, $V+\gamma K-(1+r) K$. That is why the LHS of (25) need not be written as $\max \{V+\gamma K-(1+r) K ; \alpha(V+\gamma K)\}$.

Since the credit market is assumed to be perfectly competitive, the level of investment that maximizes the social surplus, $K^{F B}$, maximizes the owner's expected payoff as well. Thus, if (25) and (26) can be both satisfied at $K^{F B}$ for some $r$ and $\alpha$, then this triple will represent the decentralized solution when the degree of softness can be agreed in the contract. This can also be shown by formally solving the owner's maximization problem

$$
\max _{K, r, \alpha} p[V+B \ln (K+1)-(1+r) K]+(1-p) \alpha(V+\gamma K)
$$

s.t. the constraints $(26)$ and $(25)$. When $(1+r) K$ is expressed from the participation constraint (26) holding with equality and substituted in the objective function and the ICC (25), both $r$ and $\alpha$ disappear from the objective function, which is then maximized

\footnotetext{
${ }^{19}$ We comment more on this term in subsection 5.2.
} 
only with respect to $K$ and the maximand is $K=K^{F B}$. Solutions for $r$ and $\alpha$ are then determined by the two equations (25) (26) having $K=K^{F B} \cdot{ }^{20}$ The solution ensures us that the first best contract is both incentive compatible for the debtor and acceptable for the creditor.

The equilibrium under soft law with endogenous determination of the degree of softness is summarized in Proposition 5 and discussed afterwards.

Proposition 5. Under soft law with endogenous determination of $\alpha$,

$$
\begin{aligned}
K_{e n}^{S} & =\frac{p B}{1-(1-p) \gamma}-1=K^{F B}, \\
r_{e n}^{S} & = \begin{cases}0 & \text { if } B \leq B_{1}, \\
\frac{1-p}{p}\left[1-\left(1-\alpha^{*}\right) \frac{V+\gamma K^{F B}}{K^{F B}}\right] & \text { otherwise, }\end{cases} \\
\alpha^{*} & = \begin{cases}0 & \text { if } B \leq B_{1}, \\
\frac{V+p B \ln \left(K^{F B}+1\right)-[1-(1-p) \gamma] K^{F B}}{V+\frac{p+(1-p) \pi}{\pi}} \gamma K^{F B} & \text { otherwise, }\end{cases} \\
S_{e n, i}^{S} & =S_{Q} .
\end{aligned}
$$

When the level of softness, $\alpha$, can be set freely by the parties in the contract, the investment will always equal the first best and the owner's expected payoff in period 0 will equal the social surplus that the social planner would achieve. The equilibrium levels of $K$ and the owner's payoff are the same as the first best levels discussed at the end of section 3 .

Figures 9 through 14 in Appendix A.2.3 illustrate the dependence of $\alpha$ and $r$ on $B$ for different values of $p, \gamma$, and $V$, respectively. As long as the incentive compatibility constraint (25) assuring that the owner will choose the safe strategy does not bind for $\left(K, r, \alpha, S_{i}\right)=\left(K^{F B}, 0,0, S_{Q}\right)$, this contract with socially optimal investment, zero

\footnotetext{
${ }^{20}$ We assume that the values of $\alpha$ and $r$ are chosen in such a way that both these constraints hold with equality, which is equivalent to choosing the minimum feasible values of $\alpha$ and $r$.
} 
interest rate, and zero degree of softness represents the optimal solution. As soon as (25) starts to bind, $\alpha^{*}$ jumps up discontinuously from zero to a positive level that ensures that the owner will choose the safe strategy. Also $r_{e n}^{S}$ jumps up to satisfy the bank's participation constraint (26). On the other hand, both $K_{e n}^{S}$ and the owner's expected profit evolve continuously and are equal to the first best.

The optimal level of $K$ increases with the probability of state $H, p$. Hence, as Figures 9 and 10 show, the ICC (25) starts to bind for $\alpha=0$ and $r=0$ at a lower level of $B$, so both $\alpha^{*}$ and $r_{e n}^{S}$ have to become positive in order to keep it satisfied. Once $\alpha^{*}$ is positive it decreases in $p$ because higher $K$ increases the expected value under quitting more than under continuation and lower $\alpha$ is thus sufficient to satisfy (25).

Figures 11 and 12 depict that higher $\gamma$ makes quitting, ceteris paribus, more attractive for the owner and, thus, for $\alpha=0$ and $r=0,(25)$ starts to bind at a higher level of $B$. Higher value under quitting also means that $\alpha^{*}$ can be lower. Higher $\pi$ would have exactly the opposite effect than higher $\gamma$; $\alpha$ and $r$ need to become positive at a lower level of $B$ and, once positive, $\alpha^{*}$ increases in $\pi$.

Finally, as shown in Figures 13 and 14, higher $V$ moderates the moral hazard problem and, thus, enables (25) to be satisfied with $\alpha=0$ and $r=0$ for higher $B$ 's. The reason is that as long as $(K, r, \alpha)=\left(K^{F B}, 0,0\right)$, higher $V$ increases the owner's payoff from quitting more than that from continuation. However, when $\alpha$ and $r$ are positive, a unit increase in $V$ raises the continuation payoff by $\alpha+(1-\alpha) \pi$, while the quitting payoff only by $\alpha$. Thus, for higher $V$, the owner needs to obtain a higher fraction of the total firm value when quitting the project in order to satisfy (25), which in turn increases the interest rate so that (26) is satisfied, too. That is why $\alpha^{*}(B, V)$ and $r_{e n}^{S}(B, V)$ are increasing in $V$ for $B$ 's above the threshold value. 


\subsection{Exogenously Given $\alpha$}

In this section, we assume that $\alpha$ is given exogenously. The extensive form representation of this game is shown in Figure 2 in Appendix A.1. As before, we are particularly interested in the effects on the debtor's strategy choice in state $L$.

In section 4 , we analyzed the special case when $\alpha$ is exogenously given as $\alpha=$ 0 . Now, we look for the generalized solution for any $\alpha$ between 0 and 1 . The first obvious difference between the specific and the generalized situation is that if the owner gambles on resurrection in state $L$ and this gamble fails, she still keeps fraction $\alpha$ of the remaining firm value. Thus, in the generalized case, $(1-\pi) \alpha V$ is added to the RHS of ICC (11) and to secure the choice of $S_{Q}$ (after $K^{F B}$ and $r=0$ has been chosen and $L$ has occurred) the following ICC must hold:

$$
V+\gamma K^{F B}-K^{F B} \geq \pi\left[V+B \ln \left(K^{F B}+1\right)-K^{F B}\right]+(1-\pi) \alpha V
$$

which, for $\alpha>0$, starts to bind at a lower $B$ than (11) does.

For $K=K^{F B}$ and $r=0$ to be the solution, the creditor, besides being sure that the debtor chooses $S_{Q}$ in state $L$, must be also certain about being repaid in full after the project has been quit. In other words, it must be ensured that the owner will not fake insolvency and file for bankruptcy to alleviate herself of part of the debt

$$
V+\gamma K^{F B}-K^{F B} \geq \alpha\left(V+\gamma K^{F B}\right) .
$$

If either (28) or (29) does not hold, the first best solution can still be achieved if $\alpha$ is such that in state $L$ the owner prefers choosing the safe strategy, voluntarily files for bankruptcy and keeps fraction $\alpha$ of the residual value, to choosing the risky strategy. In this case, however, $r$ must be positive to compensate the creditor for the risk of not being repaid in full. This situation of $K=K^{F B}$ and $r>0$ takes place when either 
(28) or (29) is violated and

$$
\alpha\left(V+\gamma K^{F B}\right) \geq \pi\left[V+B \ln \left(K^{F B}+1\right)-\left(1+r_{e x}^{S}\right) K^{F B}\right]+(1-\pi) \alpha V
$$

where $r_{e x}^{S}$ is given by solving the bank's participation constraint (holding with equality) as

$$
r_{e x}^{S}=\frac{1-p}{p}\left[1-(1-\alpha) \frac{V+\gamma K^{F B}}{K^{F B}}\right] .
$$

In this situation, soft law has the benefits discussed in the literature. It induces the owner to choose the strategy $S_{Q}$ and put the firm into reorganization instead of gambling for resurrection in state $L$. The bank, although not repaid in full in state $L$, is compensated by a higher payoff in state $H$. The elimination of excessive risk-taking in period 1 also enables the owner to carry out the initial investment in period 0 at the socially optimal level.

When neither $(28)$ nor $(30)$ is satisfied, ${ }^{21}$ the first best cannot be achieved for the given $\alpha$. The optimal contract $\left(K_{e x}^{S}, r_{e x}^{S}, S_{e x, i}^{S}\right)$ will then be determined as the solution to one of the following maximization problems:

1. $S_{Q}$ and full repayment in state $L . K$ and $r$ are set in such a way that the owner prefers $S_{Q}$ in state $L$ and the creditor gets repaid in full. The maximization problem then becomes

$$
\begin{gathered}
\max _{K, r} p[V+B \ln (K+1)]+(1-p)(V+\gamma K)-K \\
\text { s.t. } \\
V+\gamma K-K \geq \pi[V+B \ln (K+1)-K]+(1-\pi) \alpha V .
\end{gathered}
$$

\footnotetext{
${ }^{21}$ Note that violation of both (29) and (30) implies violation of (28) as well.
} 
This is similar to the situation under tough law, the only difference being the term $(1-\pi) \alpha V$ in the ICC. The optimal $K$ is obtained by solving (33) held with equality, i.e., $K_{e x}^{S}$ is given by

$$
(\gamma+\pi-1) K_{e x}^{S}-\pi B \ln \left(K_{e x}^{S}+1\right)+(1-\alpha)(1-\pi) V=0
$$

2. $S_{Q}$ and partial repayment in state $L . K$ and $r$ are set in such a way that once $L$ occurs, the owner prefers $S_{Q}$, files for bankruptcy and the creditor gets only fraction $(1-\alpha)$ of the residual value. The maximization problem takes the following form:

$$
\max _{K, r} \quad p[V+B \ln (K+1)-(1+r) K]+(1-p) \alpha(V+\gamma K)
$$

s.t.

$$
\begin{array}{r}
\alpha(V+\gamma K)-\pi[V+B \ln (K+1)-(1+r) K]+(1-\pi) \alpha V \geq 0 \\
p(1+r) K+(1-p)(1-\alpha)(V+\gamma K)-K \geq 0 .
\end{array}
$$

We can modify the maximization problem by expressing $(1+r) K$ from $(37)$ holding with equality and substituting in the objective function (35) and the ICC (36). The optimal $K$ can then be obtained by solving the modified ICC held with equality. Substituting this $K$ in the participation constraint (37), we obtain the optimal $r$.

3. $S_{C}$ in state $L$ and partial repayment after the project failure. $K$ and $r$ will be set in such a way that once $L$ occurs, the owner prefers $S_{C}$ and if the gamble does not succeed, the firm goes bankrupt and the creditor gets just 
fraction $(1-\alpha)$ of the firm's value. The maximization problem becomes:

$$
\max _{K, r}[p+(1-p) \pi][V+B \ln (K+1)-(1+r) K]+(1-p)(1-\pi) \alpha V
$$

s.t.

$$
[p+(1-p) \pi](1+r) K+(1-p)(1-\pi)(1-\alpha) V-K \geq 0
$$

Here, the optimal $K=[p+(1-p) \pi] B-1=K_{C}^{F B}<K^{F B}$. The optimal interest rate is then obtained by substituting $K_{C}^{F B}$ in the participation constraint (39) holding with equality.

When deciding which of the three possible contracts stated above is the best, the owner compares the expected payoffs to each, i.e., the values of the objective function at the optimal solution, and chooses the one with the highest payoff.

We now summarize the above derivations in the following proposition.

Proposition 6. Under soft law with exogenously given $\alpha$, the optimal levels of $K$ and $r$ are determined as follows.

- If (28) and (29) hold, $K_{e n}^{S}=K^{F B}, r_{e n}^{S}=0, S=S_{Q}$.

- If either (28) or (29) does not hold but (30) holds, $K_{e n}^{S}=K^{F B}, r_{e n}^{S}$ is given by (31), and $S=S_{Q}$.

- In all other cases, i.e., if neither (28) nor (30) holds, the owner will solve problems 1 through 3 above and choose the maximizing values of $K$ and $r$ in the problem that leads to the highest expected payoff.

Simulations of the dependence of optimal $K, r$, and the owner's payoff on $B$ and $\alpha$ are provided in Figures 15 through 17 in Appendix A.2.4. Figure 15 shows that if 
$\alpha$ is high enough, the first best can be achieved. This is the case for $\alpha=0.5$ which is sufficient to induce the owner to choose $S_{Q}$ for all levels of $B$. If $\alpha$ is not high enough to cause the owner to choose $S_{Q}, K$ essentially follows the same pattern as under tough law. $K$ is first identical with the first best and the owner chooses $S_{Q}$. For $B^{\prime} s$ above a certain level, choosing $S_{Q}$ is made credible only by decreasing $K$ below $K^{F B}$. When ensuring $S_{Q}$ by further decreasing $K$ becomes too costly, the $S_{C}$ becomes the strategy to be chosen in state $L$ and optimal $K$ is adjusted accordingly, i.e., it jumps upward to its optimal level given the choice of $S_{C}$ in state $L$. The difference is, as already mentioned above, that $S_{C}$ is now more attractive due to the APR violation after the project failure, so the constraint making $S_{Q}$ incentive compatible starts to bind for lower $B$, and $K$ starts to fall earlier than under tough law. This effect of soft law is also discussed by Bebchuk (2001). Figures 16 and 17 then show the optimal interest rate and corresponding owner's expected payoff, respectively.

In addition to these figures, we can discuss the effects of $\gamma, p, \pi$, and $V$. It is clear that higher $\gamma$ makes $S_{Q}$ more attractive and, thus, the incentive compatibility constraint (33) starts to bind at higher $B$. Once the optimal strategy switches from $S_{Q}$ to $S_{C}, \gamma$ no longer plays a role.

Higher $p$ means higher $K$, both under $S_{Q}$ and under $S_{C}$. This also means that the incentive compatibility constraint (33) starts to bind at a lower level of $B$. In the region where $S_{C}$ is the optimal strategy, higher $p$ is associated with a lower interest rate because the probability of project failure, $(1-p)(1-\pi)$, is lower and the bank is more likely to be repaid in full.

Higher $\pi$ means that $S_{C}$ is more attractive and the ICC (33) starts to bind at a lower $B$. Thus, $K$ starts to fall earlier. Once $S_{C}$ become the optimal strategy, higher $\pi$ means higher optimal $K$. Similar effects hold for the owner's expected payoff and the interest rate. Higher $\pi$ means that they deviate from their respective optimal values 
at a lower level of $B$ but their second best levels are then closer to the first best.

As for $V$, when it increases, it essentially enables the owner to choose $S_{Q}$ for even higher $B$ 's, and once $S_{C}$ becomes optimal, higher $V$ is associated with a lower distortion away from the first best, i.e., a higher profit and lower interest rate. This is the same as under tough law.

\section{Possibility of Verification under Tough Law}

In this section, we return back to the tough law setup and inspect the possibility of creditors' verification of the firm's situation in period 1 as an alternative solution to the gambling on resurrection problem under some circumstances. In other words, we assume $\alpha$ to be zero and introduce a new parameter to the analysis: the cost of verification, $c$. For the extensive form representation of the game, see Figure 3 in Appendix A.1.

The debtor would like to commit to the socially efficient strategy, $S_{Q}$, ex-ante, because this would enable her to obtain credit in the amount of $K^{F B}$ and would maximize the owner's expected payoff. However, since the state of the world is the debtor's private information, such a commitment would not be credible if ex post, in state $L$, the debtor would prefer $S_{C}$. In section 4 , we assumed that the only way to make the debtor's commitment to $S_{Q}$ credible is through setting $K$ low enough. In section 5, the violation of APR was introduced as a way to make the debtor follow the safe strategy. In this section, we instead introduce the possibility that the bank is able to verify, at a certain cost, the firm's report of the state.

If the firm, represented by the owner, reports state $H$, the bank can decide to verify this information which costs it $c$. We assume a perfect monitoring technology: if the bank decides to verify this information, it will learn the true state with certainty. 
If it finds the state is $H$, nothing happens and the project continues to period 2. If it uncovers misreporting, i.e., if it finds that the state is $L$, it will take control over the business and obtain either the full payoff $(1+r) K$ or the entire firm value $V+\gamma K$, whichever amount is smaller. We also assume that following the discovery of misreporting, the owner obtains nothing even if the bank is paid in full. This reflects the fact that the bank is in control, and it will not exert any effort to obtain value in excess of $(1+r) K$.

Note that were we not assuming this punishment of the owner following the bank's discovery of the owner's misreporting, partial verification would never be sufficient to induce the owner to choose $S_{Q}$ in situations in which she, without verification, would prefer $S_{C}$. This is simply because she could never do worse by lying than by telling the truth. Full verification would always be necessary in this case.

Depending on the parameter values, the optimal solution for $\left(K, r, S_{i}\right)$ and $q$ can take four different forms:

1. First best without verification, $\left(K^{F B}, 0, S_{Q}\right)$ and $q=0$. After contracting for $K=K^{F B}$ and $r=0$, the debtor chooses $S_{Q}$ after $L$ even without verification. Note that this is the case of $B \leq B_{1}(p, \pi, \gamma, V)$.

2. Second best without verification, $\left(K<K^{F B}, 0, S_{Q}\right)$ and $q=0$. At $K=$ $K^{F B}$ the owner would choose $S_{C}$, but lowering $K$ below the first best level costs her less than facing the risk of being punished for misreporting.

3. Second best under probabilistic verification, $\left(K<K^{F B}, \frac{p c q}{K}, S_{Q}\right)$ and $q>0$. Without verification the owner would choose $S_{C}$, but a probabilistic verification $(0<q<1)$ is sufficient to induce her to choose $S_{Q}$. This is the case when full repayment is possible following the choice of $S_{Q}$, i.e., the owner still receives a certain payoff following the choice of $S_{Q} . K<K^{F B}$ because 
the marginal cost of increasing $K$ is higher than in the social planner's problem by $\partial q / \partial K$. The bank has to be compensated for the verification cost $q c$, thus $r=q c / K>0$.

4. First best under full verification, $\left(K^{F B}, \frac{c}{K^{F B}}+\frac{1-p}{p}\left(1-\gamma-\frac{V}{K^{F B}}\right), S_{Q}\right)$ and $q=1$. If full repayment is impossible after the choice of $S_{Q}$ in state $L$, the owner would choose $S_{C}$ for any $q<1$. In order to induce the owner to choose $S_{Q}$ we, therefore, need to have $q=1$. At this level of $q$, the marginal cost of increasing $K$ is the same as in the social planner's problem (since $\frac{\partial q}{\partial K}=0$ ), and we will have $K=K^{F B}$. The interest rate will again compensate the bank for the verification cost and also for the risk of less than full repayment after $S_{Q}$ is chosen in state $L$. We therefore have $K=K^{F B}, r=\frac{c+(1-p)[(1-\gamma) K-V]}{p K}>0$, and $q=1$.

5. Allowing for continuation, $\left(K_{C}^{F B}<K^{F B}, \frac{1-[p+(1-p) \pi]}{p+(1-p) \pi}\left(1-\frac{V}{K_{C}^{F B}}\right), S_{C}\right)$ and $q=$ 0 . The owner may always offer a contract involving the choice of $S_{C}$ in state $L$ if she compensates the bank for the risk of less than full repayment in the case of project failure. She will do so if her profit from this contract is higher than from a contract involving verification.

From these alternatives, the owner will propose such a contract that yields her the highest expected payoff. Cases 1,2 and 5 are the same as under tough law without verification. In what follows, we analyze problems 3 and 4 in more detail. Before that, however, we make some comments common to both of them.

First, we assume that the creditor can credibly commit to verify the debtor's report with the probability $q^{*}(K, r)$ ex ante. ${ }^{22}$ Otherwise, the creditor would have an inconsistency problem: he would like to commit to verify with probability $q^{*}$, but, once this

\footnotetext{
${ }^{22}$ This is a realistic assumption in the sense that banking business is based on trust and, thus, the bank's commitment is actually enforced by the other business it has. Committing to verification and then not doing it would have a reputational cost for the bank.
} 
commitment was made and the debtor adapted her behavior in the desired way, to renounce this commitment and save the $\operatorname{cost} c$. We would then have mixed-strategy equilibria which would complicate the analysis and lead us away from the point of our interest.

Second, unlike in the situation without verification, the expected payment of the firm to the bank is $K+p c q^{*}(K, r)>K$. If there is verification, the interest serves to compensate the bank for a real verification cost that it incurs, not (or not only) for the risk of less than full repayment. Compared with the social planner solution, the verification cost is therefore a source of inefficiency.

And, finally, notice that the creditor will not want to increase $q$ above $q^{*}(K, r)$ because this increases his cost without any increase in return; the owner will already choose $S_{Q}$ anyway. Also, because of the discontinuity in the returns to increasing the verification probability $q$, for $\underline{q}<q^{*}(K, r)$, the bank will only induce the choice of $S_{Q}$ with probability $q=\underline{q}$, but for $q=q^{*}(K, r)$ the owner will always prefer $S_{Q}$; the bank will either decide to set the level of $q$ equal to $q^{*}(K, r)$ or not verify at all. Any intermediate level of $q$ cannot be optimal.

\subsection{Probabilistic Verification}

Consider first the problem when full repayment is possible following the choice of $S_{Q}$ in state $L$ and, therefore, probabilistic verification is sufficient. This is the case when for the optimal $K$ and $r$ the following inequality holds:

$$
V+\gamma K \geq(1+r) K
$$


The firm's maximization problem is then

$$
\begin{gathered}
\max _{K, r}\{V+p B \ln (K+1)+(1-p) \gamma K-(1+r) K\} \\
\text { s.t. } \\
V+\gamma K-(1+r) K \geq(1-q) \pi[V+B \ln (K+1)-(1+r) K], \\
r K \geq p c q .
\end{gathered}
$$

Equation (42) is the incentive compatibility constraint which ensures that the owner will prefer $S_{Q}$. It is the analogue of (11) in the case without verification, the difference being in the probability $(1-q)$ that misreporting will be discovered and the owner will receive nothing. Equation (43) is the participation constraint. We can express the optimal $q$ from (42) held with equality as $q^{*}(K, r)=1-\frac{V+\gamma K-(1+r) K}{\pi[V+B \ln (K+1)-(1+r) K]}$, substitute it into (43) and solve the modified maximization problem. This yields the following first order conditions:

$$
\begin{aligned}
(K) \quad p \frac{B}{K+1}+(1-p) \gamma-(1+r)+\lambda\left[r-p c q_{K}^{*}(K, r)\right] & =0, \\
(r) & -K+\lambda\left[K-p c q_{r}^{*}(K, r)\right]=0 .
\end{aligned}
$$

Using (45) to express $\lambda$ and substituting back to (44) yields

$$
p \frac{B}{K+1}+(1-p) \gamma-(1+r)+\frac{K\left[r-p c q_{K}^{*}(K, r)\right]}{K-p c q_{r}^{*}(K, r)}=0
$$

From equation (46) and from the participation constraint (43) holding with equality, we can obtain the optimal levels of $K$ and $r$ for the situation when the creditor verifies 
the firm's report in period 1 with probability $q \in(0,1)$, i.e., $K_{p}^{V}(q)$ and $r_{p}^{V}(q) .{ }^{23}$

Let $F_{C}$ denote the firm's payoff from strategy $S_{C}$ (if successful) and $F_{Q}$ the firm's payoff from strategy $S_{Q}$. Differentiating $q^{*}(K, r)$ with respect to $K$ and $r$, we obtain

$$
\begin{aligned}
q_{K}^{*} & =\frac{[(1+r)-\gamma] F_{C}-\left[(1+r)-\frac{B}{K+1}\right] F_{Q}}{\pi\left(F_{C}\right)^{2}} \geq 0, \\
q_{r}^{*} & =\frac{K\left(F_{C}-F_{Q}\right)}{\pi\left(F_{C}\right)^{2}} \geq 0 .
\end{aligned}
$$

Because $q_{r}^{*} \geq 0$ and from (45) $\lambda=\frac{K}{K-p c q_{r}^{*}}$, we have $\lambda \geq 1$; the shadow cost associated with the constraint is in general higher than one. This means that in this regime increasing the amount borrowed, $K$, by one dollar increases the expected costs (here the value of the debt) by more than one dollar because the verification probability $q$ needs to be increased as well. This formally shows what we have already mentioned before, namely the fact that with probabilistic verification we will have $K<K^{F B}$.

The optimal probability of verification, $q^{*}(K, r)$, does not depend on $c$, but $c$ affects whether verification will or will not be used. If the creditor verifies with probability $q^{*}(K, r)$, the owner will always choose $S_{Q}$ and the bank will always be repaid in full. The gain from verification for the bank is $(1-p)(1-\pi)[(1+r) K-V]$ and the cost is $p c q^{*}(K, r)$. The bank will, therefore, want to verify the firm's report if

$$
c \leq \frac{(1-p)(1-\pi)}{p q^{*}\left(K_{p}^{V}, r_{p}^{V}\right)}\left[\left(1+r_{p}^{V}\right) K_{p}^{V}-V\right]
$$

Proposition 7. Under tough law with verification, as long as for optimal $K, r$, and $q$ inequalities (40) and (49) hold,

\footnotetext{
${ }^{23}$ The superscript $V$ denotes a tough law regime with verification, while the subscript $p$ denotes partial verification.
} 
$K_{p}^{V}, r_{p}^{V}$, and $q^{*}$ are given by the system of equations

$$
\begin{aligned}
q^{*} & =1-\frac{V+\gamma K_{p}^{V}-\left(1+r_{p}^{V}\right) K_{p}^{V}}{\pi\left[V+B \ln \left(K_{p}^{V}+1\right)-\left(1+r_{p}^{V}\right) K_{p}^{V}\right]}, \\
r_{p}^{V} & =\frac{p c q^{*}}{K_{p}^{V}}, \\
0 & =p \frac{B}{K_{p}^{V}+1}+(1-p) \gamma-\left(1+r_{p}^{V}\right)+\frac{K_{p}^{V}\left[r_{p}^{V}-p c q_{K}^{*}\right]}{K_{p}^{V}-p c q_{r}^{*}},
\end{aligned}
$$

and $S_{i}^{V}=S_{Q}$.

\subsection{Full Verification}

Consider now the problem when following the choice of $S_{Q}$ in state $L$ full repayment is impossible and the owner receives nothing, i.e., when (40) is violated for the optimal $K$ and $r$. Because $S_{C}$ offers her a positive payoff with at least some probability, she would never choose $S_{Q}$ for $q<1$. We may, therefore, assume $q=1$. In this case the firm's maximization problem can be written as

$$
\begin{gathered}
\max _{K, r} \quad p[V+B \ln (K+1)-(1+r) K] \\
\text { s.t. } \\
p[(1+r) K-c]+(1-p)(V+\gamma K)-K \geq 0 .
\end{gathered}
$$

Because the bank verifies with probability 1 , the expected verification cost is $c$. The first order conditions are:

$$
\begin{aligned}
(K) \quad \frac{p B}{K+1}-(1+r) p+\lambda[p(1+r)+(1-p) \gamma-1] & =0, \\
(r) & -p K+\lambda p K=0 .
\end{aligned}
$$


From the FOC for $r$, we have $\lambda=1$. Using this in the FOC for $K$, we can obtain the solution for $K$ :

$$
K_{f}^{V}=\frac{p B}{1-(1-p) \gamma}-1=K^{F B}
$$

The intuition for this result is that in this regime, the verification probability is fixed, $q=1$, and, therefore, the verification cost that the bank needs to be compensated for is fixed as well at $r K=c$. Therefore, increasing $K$ by one dollar increases the expected cost (the expected value of the debt) also by one dollar which is the same as in the social planner's problem. Substituting $K^{F B}$ to the participation constraint (51) holding with equality, we obtain the following solution for $r$ :

$$
r_{f}^{V}=\frac{c}{K^{F B}}+\frac{1-p}{p}\left(1-\gamma-\frac{V}{K^{F B}}\right)
$$

Because the gain from verification for the bank is $(1-p)[V+\gamma K-\pi(1+r) K-$ $(1-\pi) V]$ and the cost of full verification is $p c$, the bank will want to verify the firm's report if

$$
c \leq \frac{1-p}{p}\left\{\pi V+\left[\gamma-\pi\left(1+r_{f}^{V}\right)\right] K^{F B}\right\}
$$

Proposition 8. Under tough law with verification, as long as for optimal $K$ and $r$ inequality (40) is violated and inequality (56) is satisfied,

$$
\begin{aligned}
K_{f}^{V} & =\frac{p B}{1-(1-p) \gamma}-1=K^{F B}, \\
r_{f}^{V} & =\frac{c}{K^{F B}}+\frac{1-p}{p}\left(1-\gamma-\frac{V}{K^{F B}}\right), \\
q^{*} & =1, \\
S_{f, i}^{V} & =S_{Q} .
\end{aligned}
$$




\subsection{Optimal Contract}

In the beginning of section 6 , we described five types of contracts under tough law with the possibility of verification. While contracts 1, 2, and 5 are defined in Proposition 4, contracts 3 and 4 are defined in Propositions 7 and 8, respectively. Now, we pull these options together and examine how the debtor's choice between these contracts in the beginning of the game depends on the model's parameters. We provide our findings by means of simulations. Figures 18 through 21 in Appendix A.2.5 depict the dependence of $K, r, F_{0}$ and $q$ on the upside, $B$, and on the cost of verification, $c$.

For $B^{\prime} s$ such that (13) holds, i.e., for $B \leq B_{1}$, the solution is the same as under tough law and is identical with the first best. This represents the first part of the line in Figure 18 common to all levels of $c$. Above this level of $B, K=K^{F B}$ is not incentive compatible without verification. It first pays to decrease $K$ below its first best level, irrespective of the value of $c$. However, $c$ affects how much $K$ will be decreased. The point where $K$ starts to rise indicates where verification starts to be used and this occurs earlier for lower $c$. For $c=0.2$ and $c=0.3$, the payoff from $S_{C}$ eventually exceeds that from $S_{Q}$ at a certain level of $B$. At this $B, K$ falls discontinuously to $K_{C}^{F B}$.

The interest rate, depicted in Figure 19, becomes positive when verification starts to be used. As mentioned above, it compensates the bank for the verification cost and, therefore, is lower for lower $c$. When $S_{C}$ becomes the owner's optimal strategy, the role of the interest rate changes; it compensates the bank for the risk of less than full repayment, as under the case without verification. At this point, the interest rate jumps upward.

The owner's payoff, depicted in Figure 20, is the same for all levels of $c$ as long as verification is not used. From this point on, the lowest $c$, naturally, is associated with the highest expected payoff. When $S_{C}$ becomes the optimal strategy, $c$ does not 
affect expected payoff any longer and, therefore, from this point on, it is the same for $c=0.2$ and $c=0.3$.

Figure 21 shows that higher $c$ means that verification starts to be used $(q>0)$ at higher $B$ and stops to be used at lower $B$.

\section{Allowing for Renegotiation}

So far, we have assumed away the possibility of renegotiation. Now, although we believe and argue below that this is not an unreasonable assumption, we will consider how the situation changes when renegotiation is allowed. ${ }^{24}$ The first argument for the reasonability of not including renegotiation in the basic setup is that the bank may want to build a reputation of not being willing to renegotiate in order to prevent strategic defaults by other debtors. In our model, the bank does not need such reputation because the debtor has nothing to gain from defaulting after the project succeeded (we assume all the firm's value consists of verifiable assets so the bank could enforce the payment through court). However, in reality, strategic default may be an issue for the bank, and the bank may have an incentive to develop such a reputation. The second reason is that under renegotiation, the bank effectively forgives a part of the debtor's non-contingent payment specified in the contract. Although what the bank obtains may be more than its expected payoff from refusing to renegotiate, relevant laws may treat such debt forgiving by bank officers as illegal.

We describe the effects of renegotiation for the case of tough law and then only mention the differences under soft law. The only node in the game where renegotiation can take place is state $L$ in period 1 . In addition, considering renegotiation only makes sense in the suboptimal case when the first best cannot be reached, i.e., for $B>B_{1}$ as defined in equation (13). In this case, the debtor has an incentive to

\footnotetext{
${ }^{24}$ For a general analysis of debt-renegotiation under bankruptcy see, e.g., ?).
} 
continue the project although the action maximizing the firm's value is to quit the project. Therefore, there is space for mutually advantageous renegotiation of the initial contract.

The bargaining situation is shown in Figure 25 in Appendix A.3. The $\mathrm{x}$-axis denotes the debtor's payoff, the y-axis the bank's payoff. The maximum payoff of both is $V+\gamma K$ and the line connecting these payoffs on the $\mathrm{x}$ - and $\mathrm{y}$-axis is the Pareto frontier, with the slope -1 . In the status quo point without renegotiation, the debtor's expected payoff is $\pi[V+B \ln (K+1)-(1+r) K]$ and the bank's expected payoff is $\pi(1+r) K+(1-\pi) V$. These payoffs also determine the threat points of the debtor and the bank, denoted $P_{d}$ and $P_{b}$, respectively. The bargaining takes place between these two points on the Pareto frontier.

In state $L$, the debtor can contact the bank, reveal that state $L$ occurred and offer to quit the project if she receives a certain payoff. The maximum payoff the debtor can obtain depends on the bargaining powers of the debtor and the bank. We analyze two cases - first, when the debtor has all the bargaining power and, second, when the bank has all the bargaining power.

\subsection{Allocation of Bargaining Power}

Suppose first that all the bargaining power within the renegotiation process is possessed by the debtor, i.e., that the debtor is able to hold the bank down to its threat point $P_{b}$ where its payoff is $\pi(1+r) K+(1-\pi) V$. The debtor's payoff from renegotiation in state $L$ is, therefore, $V+\gamma K-\pi(1+r) K-(1-\pi) V$. The bank's and debtor's payoff in the high state are the same as without renegotiation, i.e., $V+B \ln (K+1)-(1+r) K$ for the debtor and $(1+r) K$ for the bank. The debtor's maximization problem in 
period 0 can, thus, be written as

$$
\max _{K, r}[p+(1-p) \pi][V-(1+r) K]+p B \ln (K+1)+(1-p) \gamma K
$$

s.t.

$$
\mathrm{PC}: \quad[p+(1-p) \pi](1+r) K+(1-p)(1-\pi) V-K \geq 0 .
$$

If, alternatively, the bank has all the bargaining power, the debtor is held down to her threat point and her payoff from the renegotiation in state $L$ is, therefore, the same as from continuation, i.e., $\pi[V+B \ln (K+1)-(1+r) K]$. The bank captures the rest of the firm value after quitting the project, which is equal to $V+\gamma K-\pi[V+$ $B \ln (K+1)-(1+r) K]<(1+r) K .^{25}$ In state $H$ the payoffs are again the same as without renegotiation and the debtor's maximization problem can be written as

$$
\max _{K, r}[p+(1-p) \pi][V+B \ln (K+1)-(1+r) K]
$$

s.t.

PC: $\quad p(1+r) K+(1-p)\{V+\gamma K-\pi[V+B \ln (K+1)-(1+r) K]\}-K \geq 0$.

\footnotetext{
${ }^{25}$ The inequality can be explained as follows. As mentioned above, renegotiation will only take place in the suboptimal case where the debtor would prefer to continue the project at $K=K^{F B}$ while the optimal strategy is to quit the project. This means that the debtor's expected payoff from continuation is higher than from quitting and paying the bank in full. Therefore, if after quitting the debtor receives as much as she expects to gain from continuation, the bank cannot be repaid in full.
} 


\subsection{Optimal Contract under Renegotiation}

The solutions to the two alternative maximization problems are

$$
\begin{aligned}
K_{R d}^{T} & =K_{R b}^{T}=\frac{p B}{1-(1-p) \gamma}-1=K^{F B} \\
r_{R d}^{T} & =\frac{K_{R d}^{T}-(1-p)(1-\pi) V}{K_{R d}^{T}-(1-p)(1-\pi) K_{R d}^{T}}-1= \\
& =\frac{1-[p+(1-p) \pi]}{p+(1-p) \pi}\left(1-\frac{V}{\frac{p}{1-(1-p) \gamma} B-1}\right) \\
r_{R b}^{T} & =\frac{K_{R b}^{T}-(1-p)[(1-\pi) V+\gamma K-\pi B \ln (K+1)]}{K_{R b}^{T}-(1-p)(1-\pi) K_{R b}^{T}}-1= \\
& =\frac{1-[p+(1-p) \pi]}{p+(1-p) \pi}\left[1-\frac{V}{\frac{p}{1-(1-p) \gamma} B-1}-\frac{\gamma-\pi B \ln \left(\frac{p}{1-(1-p) \gamma} B\right)}{(1-\pi)\left(\frac{p}{1-(1-p) \gamma} B-1\right)}\right]<r_{R d}^{T},
\end{aligned}
$$

where subscripts $R d$ and $R b$ denote the treatment with renegotiation when all the bargaining power resides with the debtor or the bank, respectively.

We see that when renegotiation is possible then irrespective of whether the debtor or the bank is in the position of making the take-it-or-leave-it offer, the first best can be attained. The optimal investment level in both cases is $K=K^{F B}$ and the debtor follows strategy $S_{Q}$ in state $L$. The distribution of the bargaining power only affects, in a predictable way, the interest rate. The intuition behind having $r_{R d}^{T}>r_{R b}^{T}$ is the following. Because the bank is supposed to just break even in period 0, then higher payoff from renegotiation in state $L$ enables the debtor to decrease the payoff in state $H$, which means to decrease the interest rate.

Under soft law, renegotiation would also occur only in state $L$ and only if the debtor would, without renegotiation, prefer to continue the project. The situation would be similar as under tough law; only the status quo payoffs and, therefore, the threat points of the parties would shift. Renegotiation would again enable the contract 
parties to attain the first best. The interest rate would be higher than under tough law because the debtor's threat point is higher and the bank's threat point is lower, which increases the debtor's and decreases the bank's payoff from renegotiation. This holds irrespective of who has more bargaining power.

\section{Conclusion}

We now summarize the findings made in the preceding sections. As we have shown in section 4 , the moral hazard problem under tough law can prevent the owner and the bank from realizing the project at the socially optimal scale and lead to inefficient strategy choice. As shown in section 5.1, if the degree of softness, $\alpha$, can be set individually for each contract, this inefficiency can be avoided and the parties can attain the same solution as the social planner would, although at the cost of a higher interest rate.

If, on the other hand, $\alpha$ is given exogenously (as assumed in section 5.2) by the legal and institutional environment, the attainment of the first best is not guaranteed. The owner can still prefer the risky strategy because what she can obtain by quitting the project is still less than her expected payoff from continuing it. In fact, if $\alpha$ is not high enough to induce the owner to quit the project in the bad state, soft law further aggravates the moral hazard problem by increasing the payoff of continuing the project.

In our model, it turns out that $\alpha$ has to be rather high to attain the first best solution. For a given project profitability $B$, the minimum level of $\alpha$ that is sufficient is determined by the other parameters, in particular by $\pi, V$ and $\gamma$. It increases in $\pi$ and decreases in $V$ and $\gamma$. For what we consider reasonable parameter values, minimum $\alpha$ varies between 0.4 and 0.5 , a substantially higher value than found in the empirical 
studies of APR violations in Chapter $11 .{ }^{26}$ This indicates that even in the U.S. we should not expect many Chapter 11 filings (at least not in the case of owner-managed firms that we analyze) to be made at a time when most of the debt can still be repaid and to be motivated by higher payoffs from quitting than from continuation. To the contrary, most of the filings should be made either after the gamble on resurrection already took place or because the financial problems are so obvious that by continuing the owner would risk legal charges against herself.

When we allow for the possibility of verification in the tough law setup, then the inefficiency due to the moral hazard problem can be reduced for all firms and projects in the economy. The extent to which this can be done depends on the level of verification cost. As long as this cost is positive, however, the inefficiency remains present to a certain extent; when $0<q<1$, higher $K$ necessitates higher $q$ (and the verification cost $q c$ ), which in turn leads to higher interest rate. Because the interest rate increases in $K$, the marginal cost of debt is higher than under the first best and the optimal $K$ is lower than $K^{F B}$. If, on the other hand, $q=1$, the verification cost does not change in the level of $K$ and, thus $K=K^{F B}$. Even in this case, the owner's expected payoff is still lower than the first best social surplus by the verification cost.

An interesting observation concerns the fact that although the optimal $K$ and $r$ vary significantly depending on the particular bankruptcy regime, the resulting profits vary significantly less. When the regime is known ex-ante, the parties adjust to it in the optimal way to minimize the distortion from the first best.

In this paper, we focus only on the moral hazard problem associated with the risk-shifting behavior of the owner. One effect of soft law, regardless of whether $\alpha$ is high enough to attain the first best or not, is a higher interest rate. This can have a negative effect on the individually optimal level of effort spent by the owner

\footnotetext{
${ }^{26}$ See Longhofer and Carlstrom (1995) for a survey.
} 
and can lead to a moral hazard along this dimension. This problem could represent an interesting question for further research. Another possible extension of the model could lie in considering a fraction of the value of the firm, $V$, to consist in intangible or human-specific assets that can be utilized only by the manager.

The comparison of $K, r$ and owner's payoff under the first best solution, tough law, tough law with verification and soft law is graphically simulated in Figures 22 through 24 in Appendix A.2.6. We see that if $\alpha=0.3$, then the owner still prefers to continue the project in the bad state and soft law only aggravates the moral hazard in the way mentioned above. This is why the optimal $K$ has to decrease below the first best level at a lower level of $B$, the interest rate is higher and the owner's payoff lower than under tough law. If, on the other hand $\alpha=0.5$, the first best can be achieved, but at a cost of a substantially higher interest rate with potentially negative effects (not modeled here) on the owner's effort. 


\section{A Appendix}

\section{A.1 Extensive Form Representations}

\section{Tough Law}

Figure 1 provides the extensive form representation of the tough law regime as analyzed in section 4. If state $H$ occurs, the debtor continues for sure in order to get the upside payoff $V+B \ln (K+1)-(1+r) K$ (because quitting would yield him $V+\gamma K-(1+r) K$, which is lower) and the creditor is repaid in full. However, if state $L$ occurs, the debtor can either misreport and choose a risky continuation to get the upside with probability $\pi$ or safely quit. If she quits, then either she can repay full $(1+r) K$ to the bank and keep $V+\gamma K-(1+r) K$ or the residual value is insufficient for full repayment so that the debtor gets nothing and the bank gets back less than what was specified in the contract. If the debtor misreports in state $L$ and follows $S_{C}$, the creditor gets full repayment with probability $\pi$ and a partial repayment $V$ with probability $(1-\pi)$. The creditor's payoff from rejecting the offered contract in the beginning, 0, represents the outside option from which the participation constraint is derived.

When analyzing the tough law regime, we assumed $V+\gamma K \geq(1+r) K$ so that quitting the project in state $L$ does not lead to bankruptcy. Had this assumption been violated, there would be no way to induce truth-telling and the choice of $S_{Q}$ in state $L$. However, as we show in the following paragraph, that assumption did not limit our analysis in any way - whenever our solution in Proposition (4) implies $K^{T}=K^{F B}$, the assumption that $V+\gamma K \geq(1+r) K$ always holds.

\section{Soft Law}

The extensive form representation of the soft law regime with exogenous $\alpha$ analyzed in section 5.2 is shown in Figure 2. The game with endogenous determination of $\alpha$ 
Figure 1: Extensive Game under Tough Law

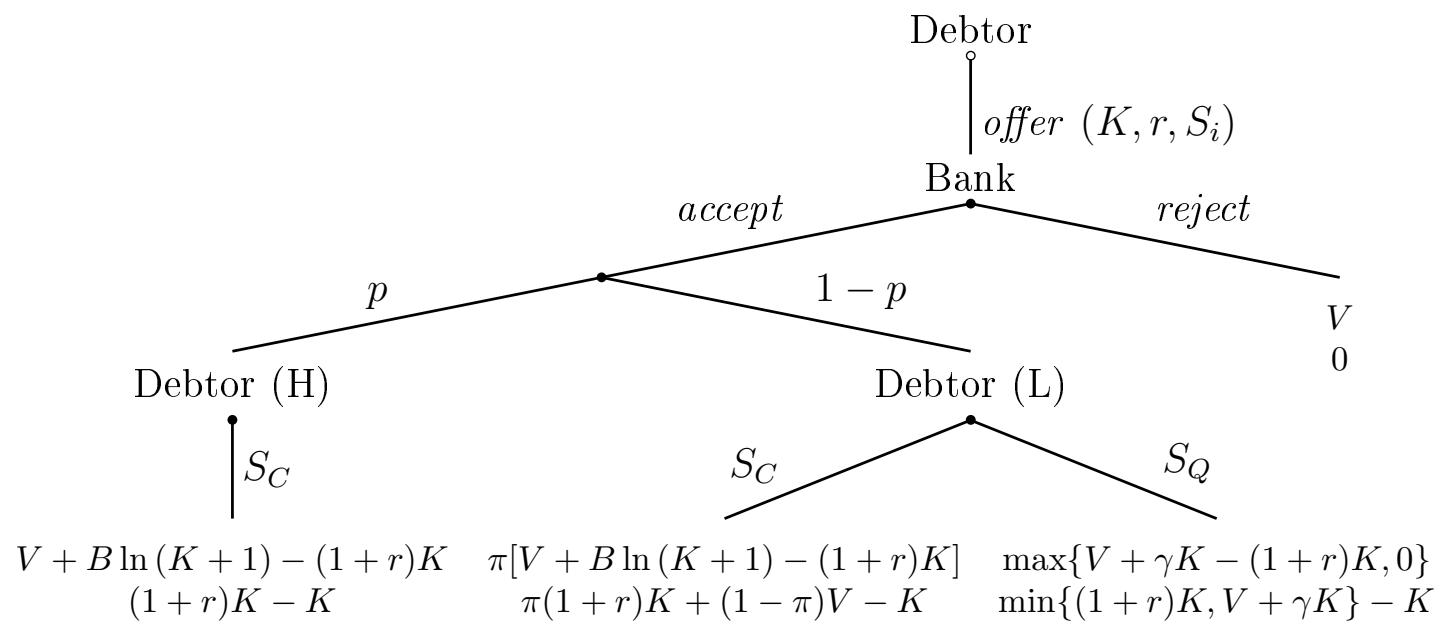

as analyzed in section 5.1 would look the same with $\alpha$ being added as the fourth parameter of the contract offered by the debtor to the creditor in period 0 .

When state $H$ occurs, the firm remains solvent and the payoffs are the same as under tough law. What changes are payoffs from both strategies after state $L$ is observed by the debtor. The debtor's payoff from continuation is increased at the expense of the creditor by $(1-\pi) \alpha V$. The debtor's payoff from quitting becomes either $V+\gamma K-(1+r) K$ with full repayment $(1+r) K$ to the creditor or $\alpha(V+\gamma K)$ with partial repayment $(1-\alpha)(V+\gamma K)-K$ to the creditor.

\section{Tough Law with Verification}

Finally, Figure 3 depicts the game under the tough law regime with verification. In addition to the situation depicted in Figure 1, the bank has a chance to verify the state of the world if the debtor claims to be in state $H$ and continues. Thus the verification cost $c q$ enters the bank's payoffs. The debtor's payoff from misreporting is decreased by fraction $q$ which represents the probability of being caught lying. 
Figure 2: Extensive Game under Soft Law

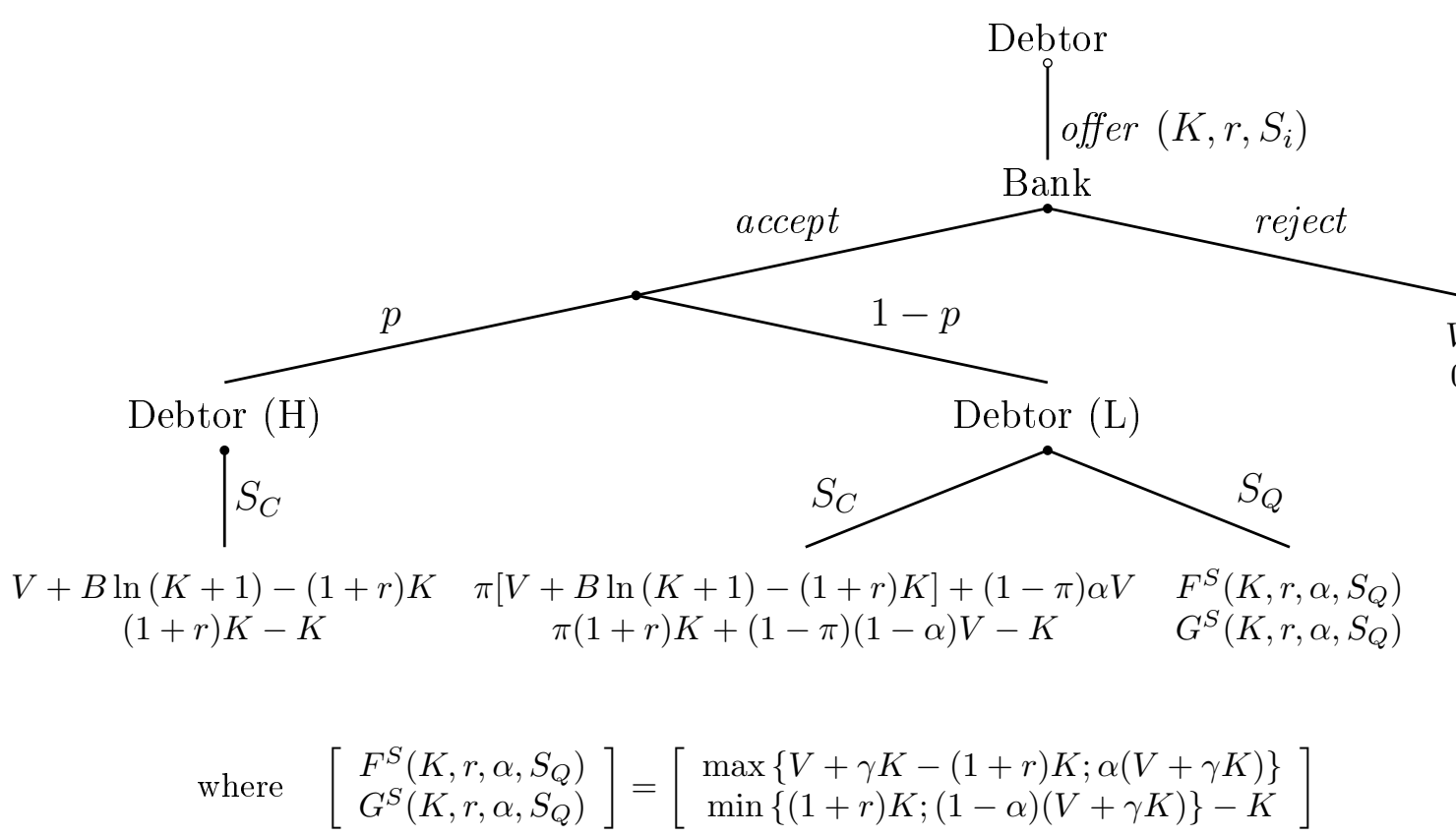

Figure 3: Extensive Game under Tough Law with Verification

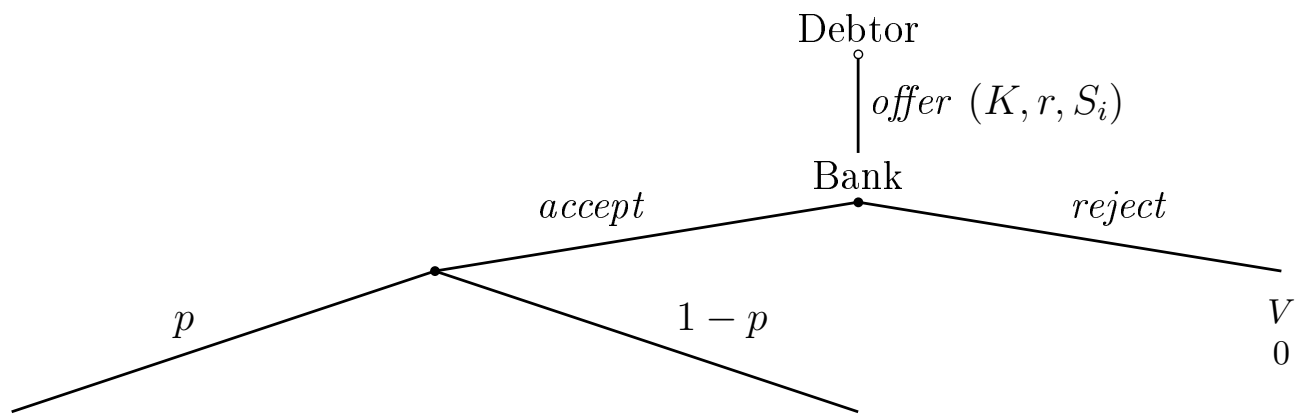

Debtor (H)

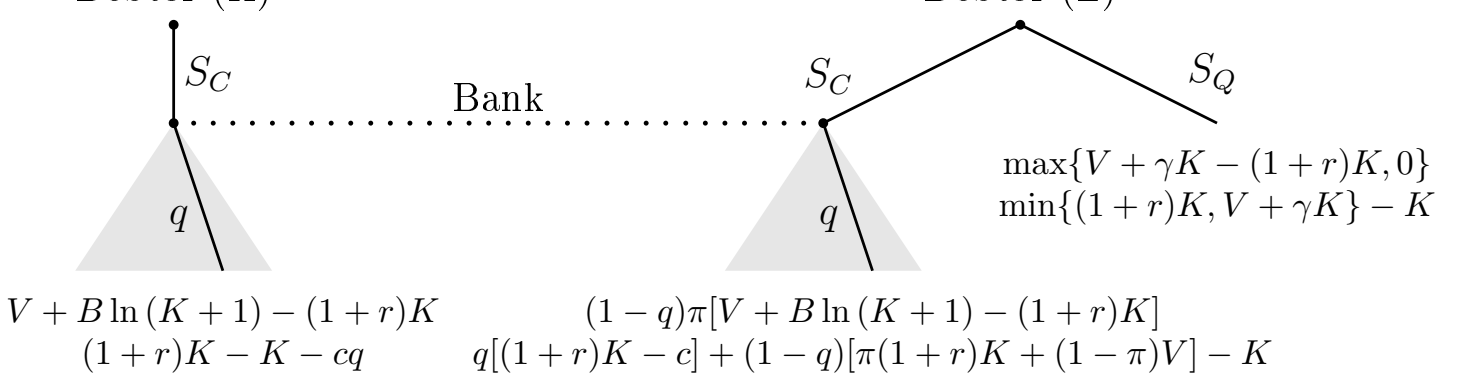




\section{A.2 Graphical Simulations}

\section{A.2.1 Social Planner}

Figure 4: Optimal Investment

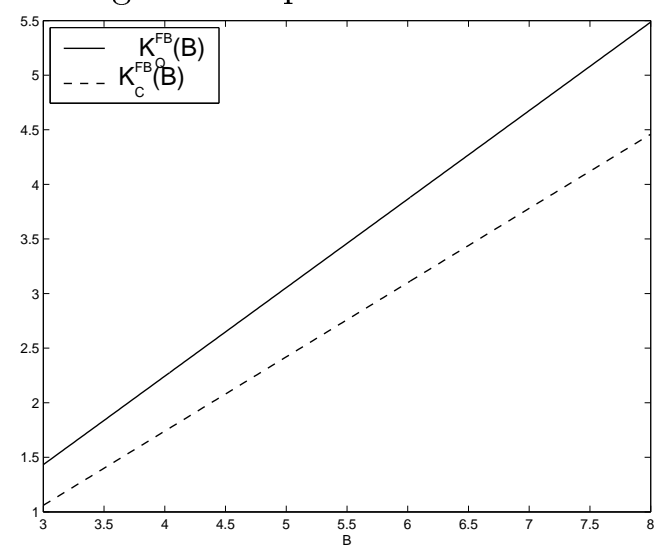

Figure 5: Social Surplus

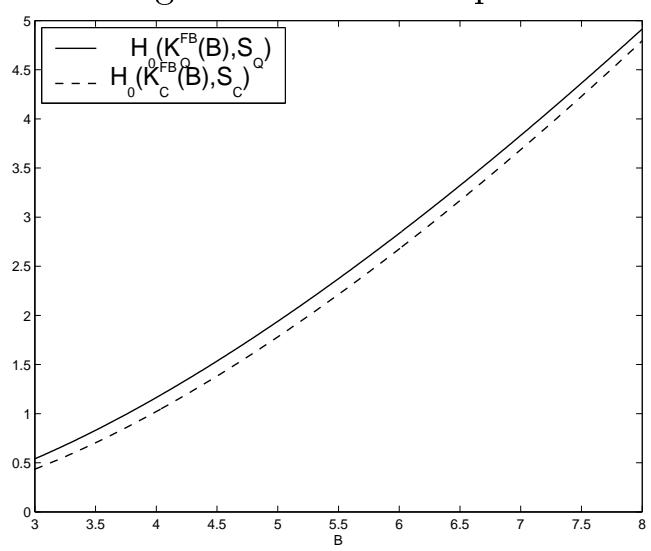

\section{A.2.2 Tough Law}

Figure 6: Debtor's Payoff from $S_{C}$ and $S_{Q}$

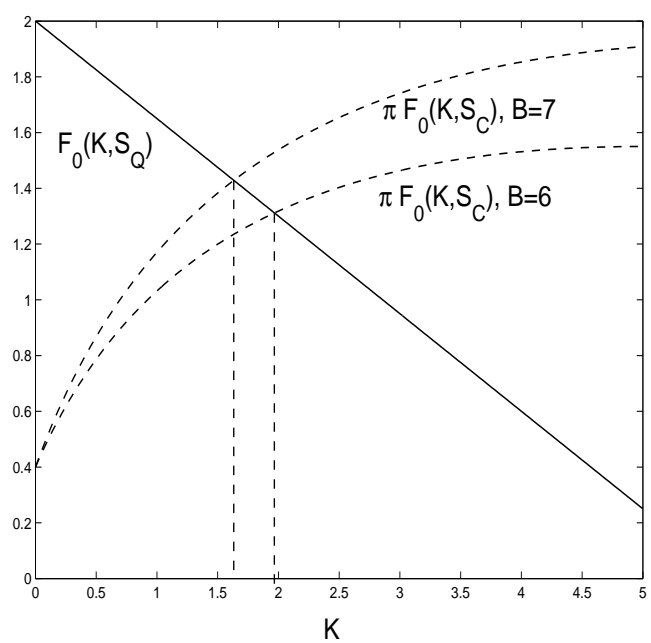


Figure 7: $K^{T}(B)$ and $K^{F B}(B)$

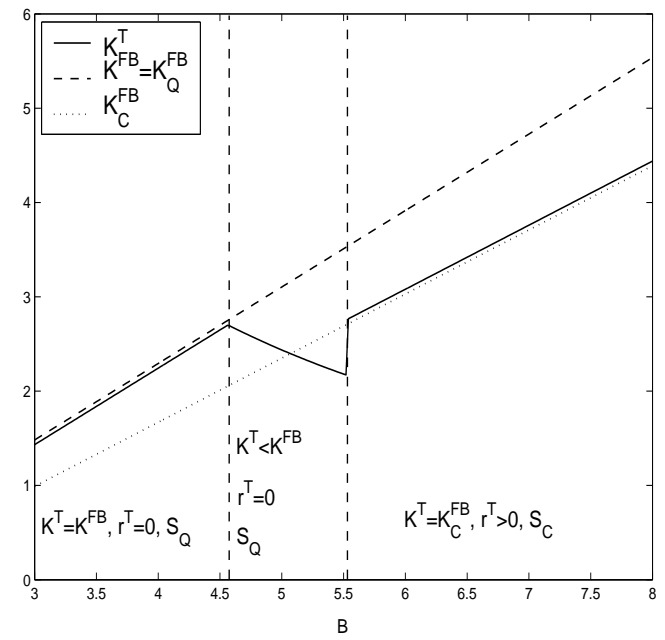

\section{A.2.3 Soft Law - Endogenous $\alpha$}

Figure 9: $\alpha_{e n}^{S L}(B, p)$

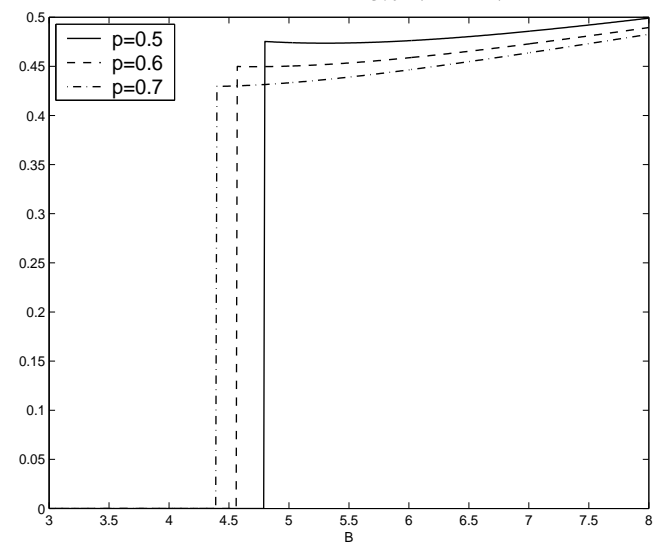

Figure 8: $\operatorname{Profit}^{T}(B)$

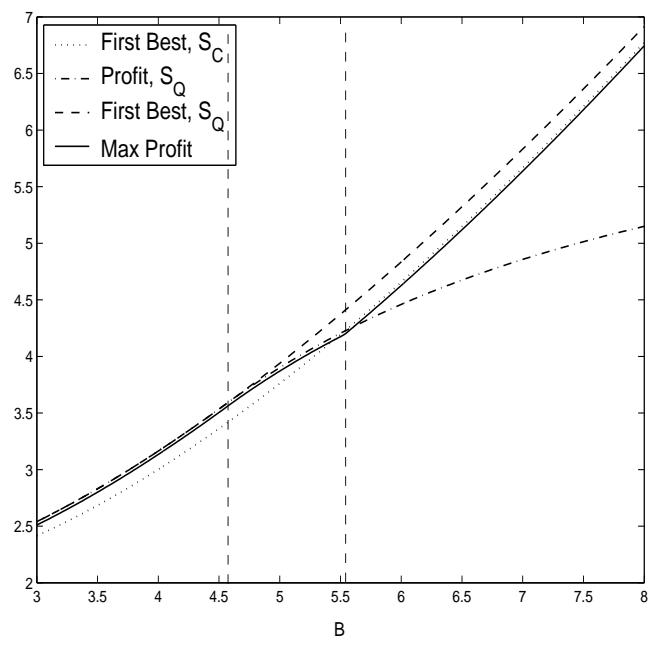

Figure 10: $r_{e n}^{S L}(B, p)$

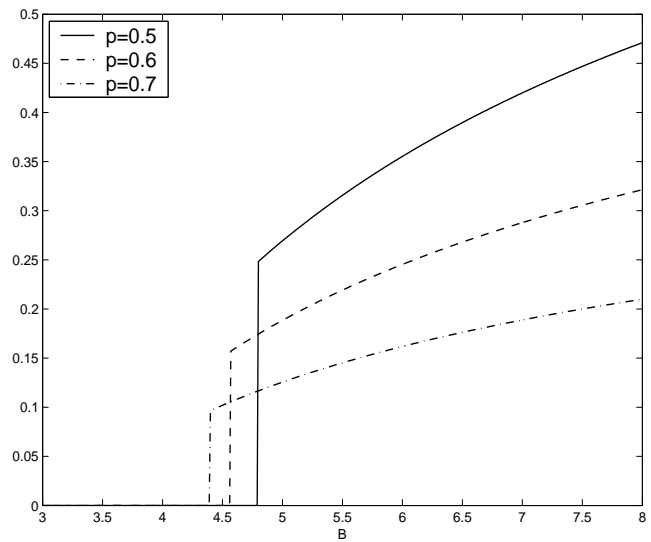


Figure 11: $\alpha_{e n}^{S L}(B, \gamma)$

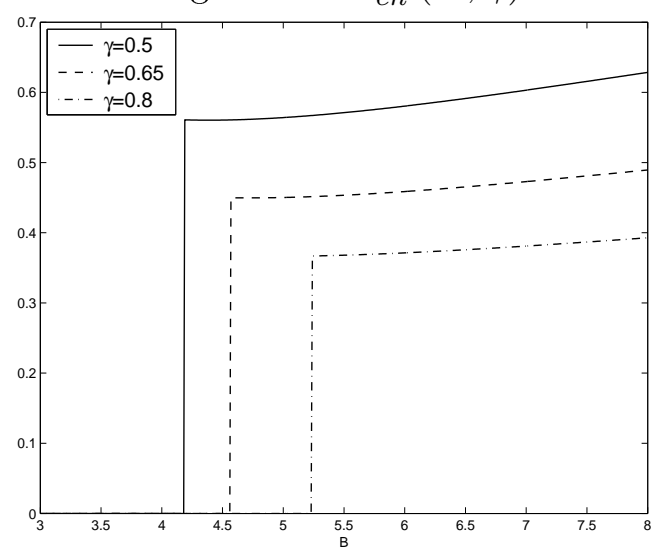

Figure 13: $\alpha_{e n}^{S L}(B, V)$

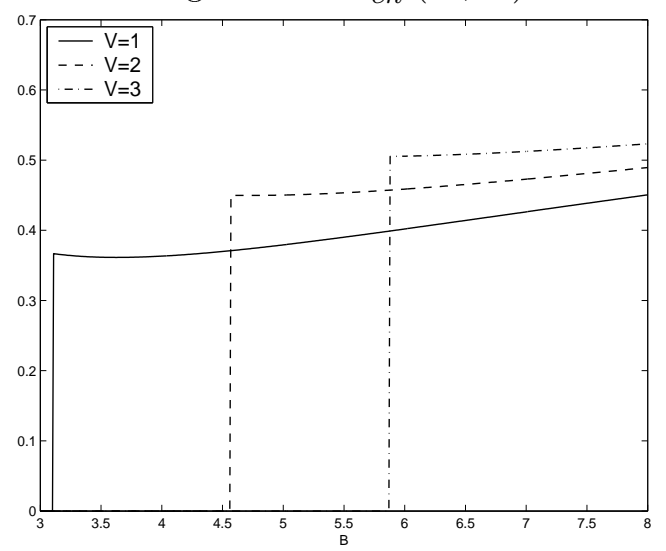

Figure 12: $r_{e n}^{S L}(B, \gamma)$

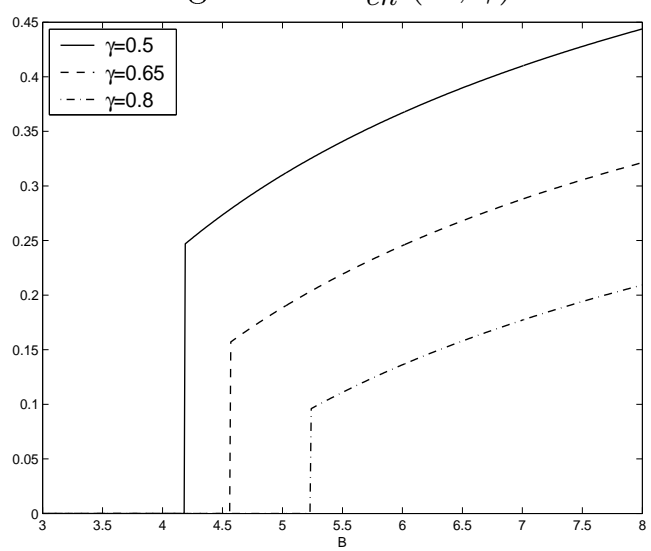

Figure 14: $r_{e n}^{S L}(B, V)$

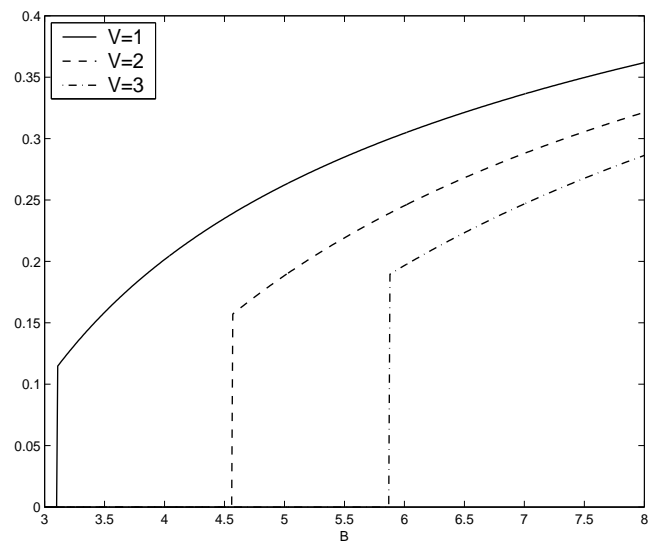




\section{A.2.4 Soft Law - Exogenous $\alpha$}

Figure 15: $K_{e x}^{S L}(B, \alpha)$

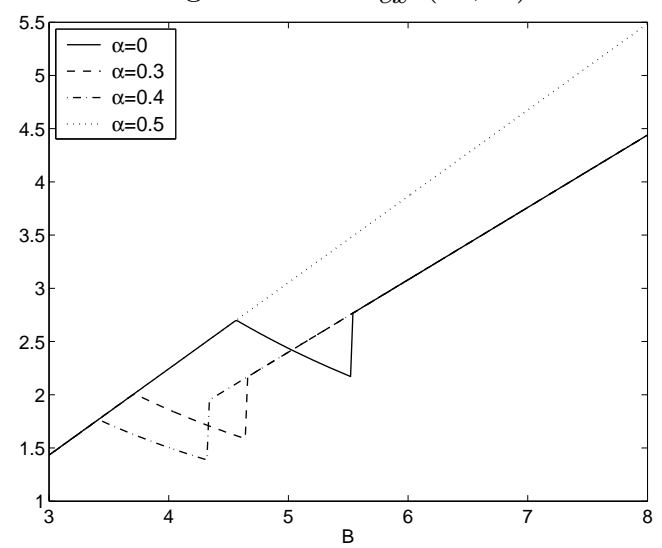

Figure 17: $\operatorname{Profit}_{e x}^{S L}(B, \alpha)$

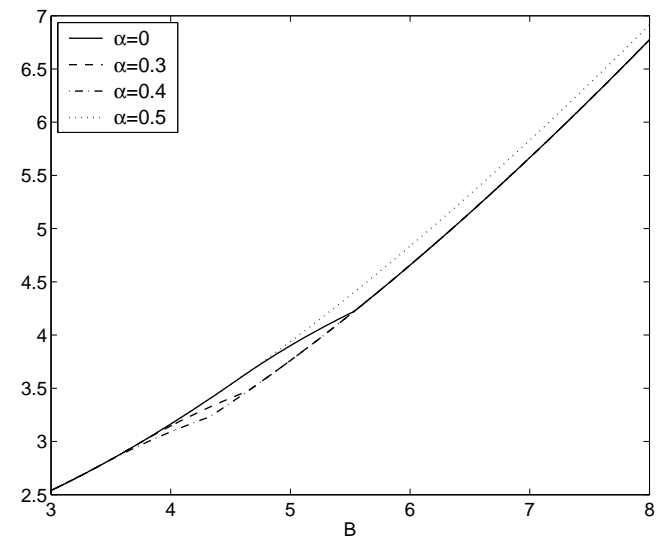

Figure 16: $r_{e x}^{S L}(B, \alpha)$

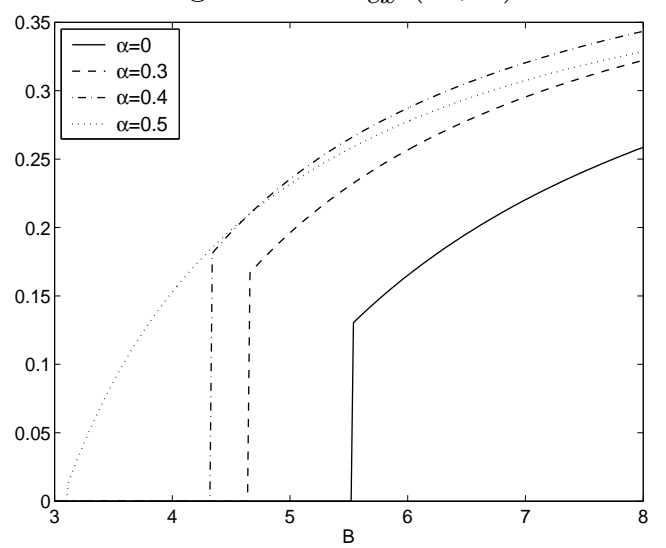




\section{A.2.5 Tough Law - Verification}

Figure 18: $K^{V}(B, c)$

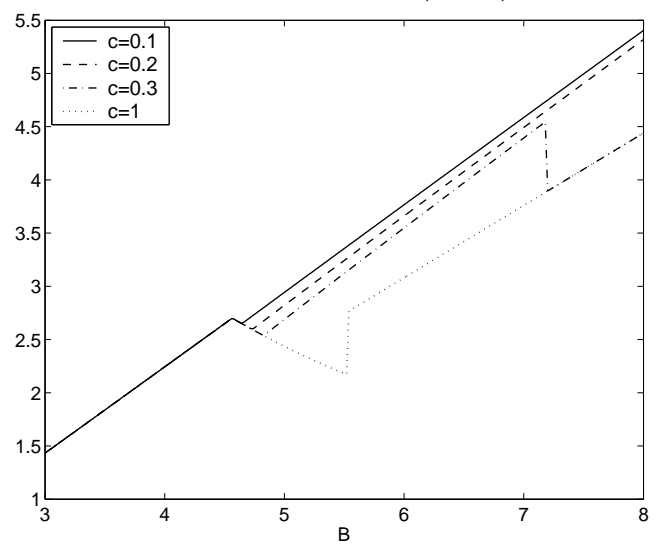

Figure 20: $\operatorname{Profit}^{V}(B, c)$

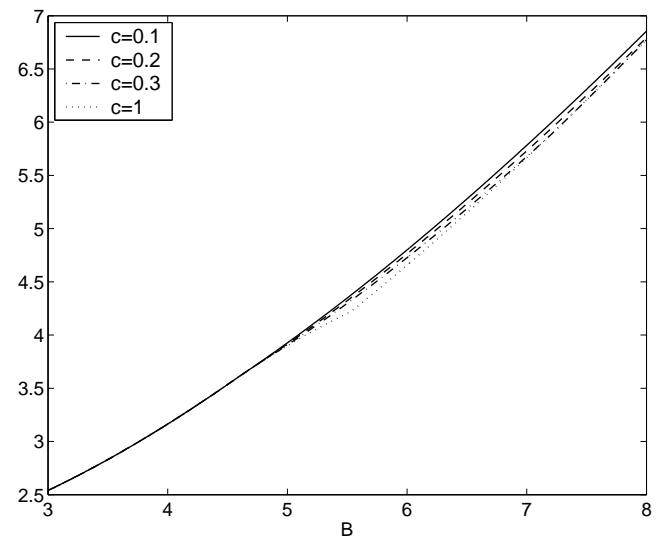

Figure 19: $r^{V}(B, c)$

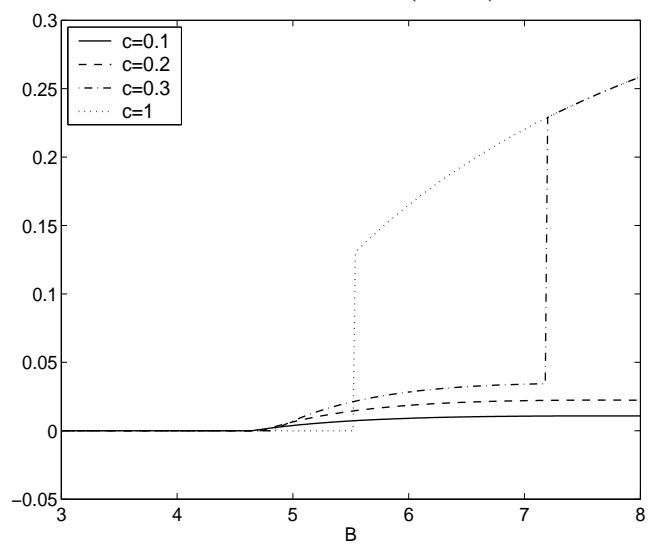

Figure 21: $q(B, c)$

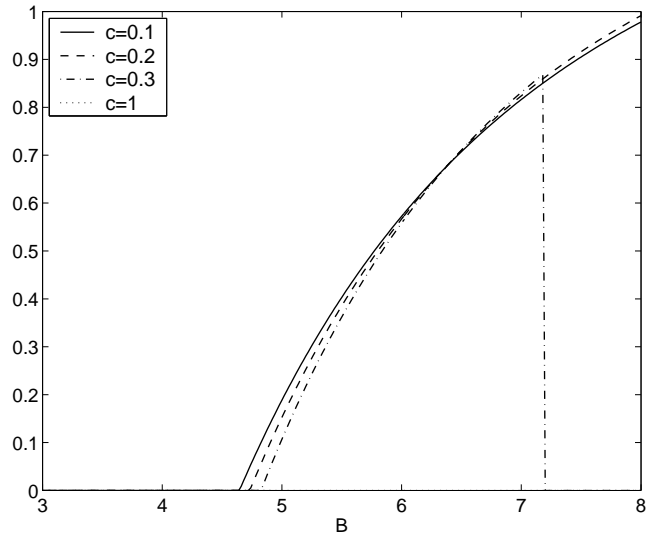




\section{A.2.6 Comparison}

Figure 22: Comparison - $K(B, \alpha)$

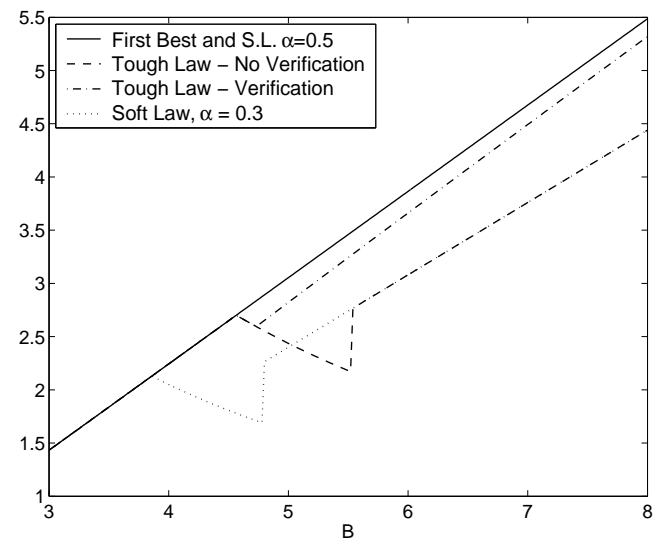

Figure 24: Comparison - Profit $(B, \alpha)$

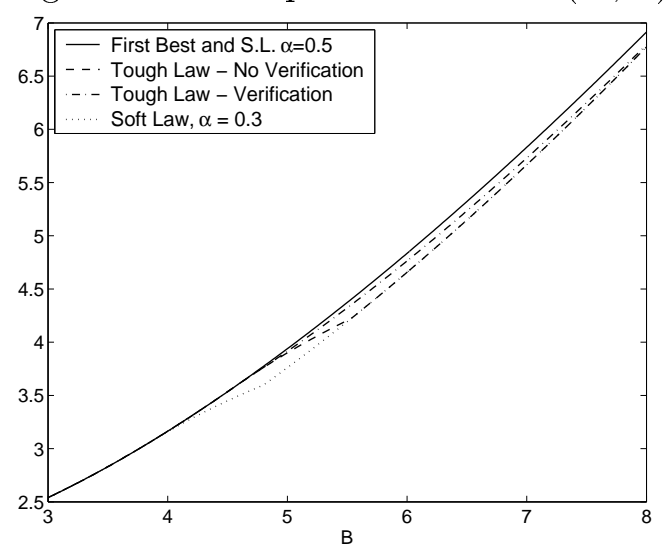

Figure 23: Comparison $-r(B, \alpha)$

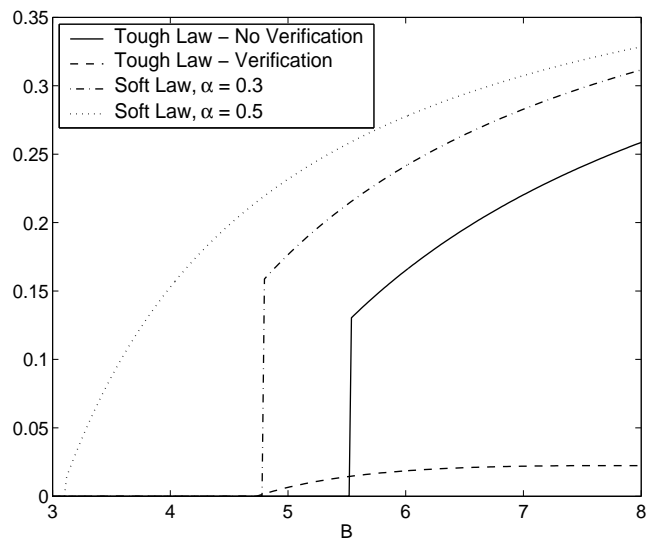




\section{A.3 Renegotiation}

Figure 25: Renegotiation

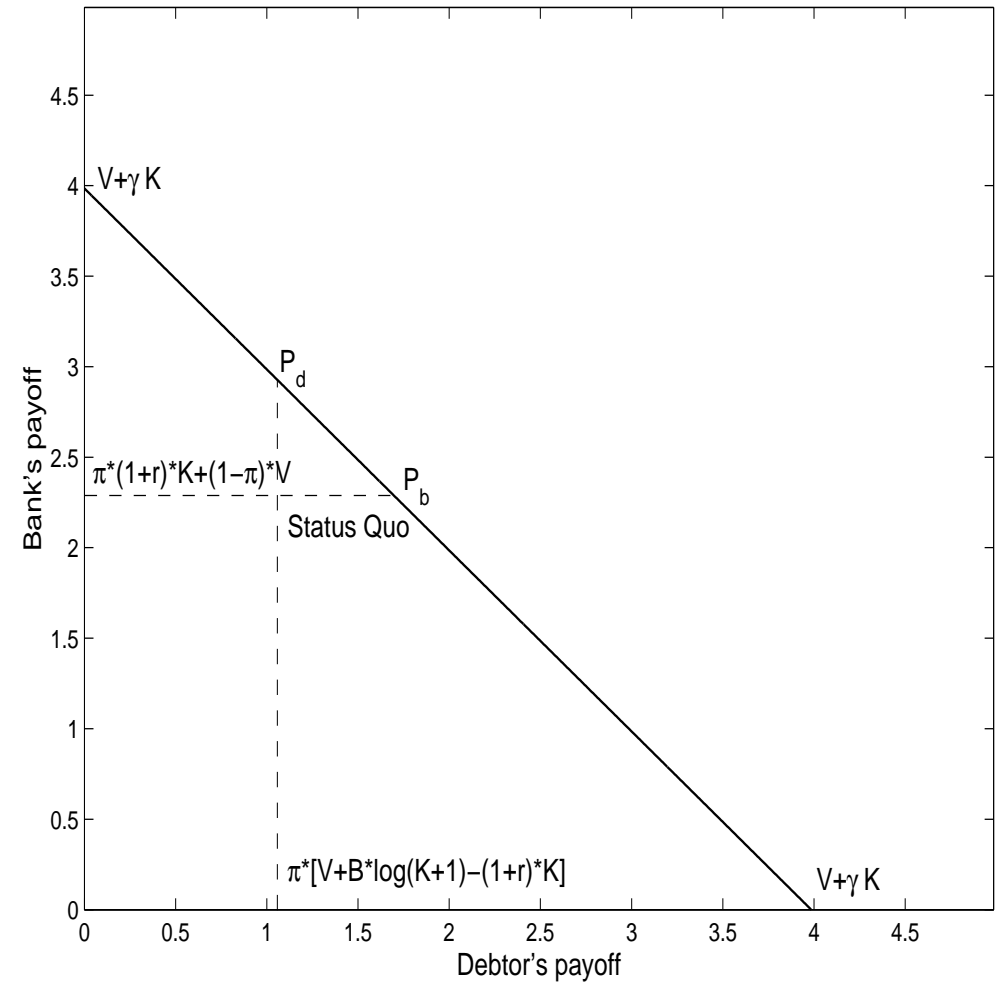




\section{A.4 Technical Appendix}

Assumption 1. Parameters $\{B, p, \pi, \gamma, V\}$ are such that

$$
B>0, \quad 0<p<1, \quad 0<\pi<1, \quad 0<\gamma<1, \quad V>0 .
$$

Assumption 2. Denote $Z \equiv \frac{p^{p}}{[1-(1-p) \gamma]^{p}[p+(1-p) \pi]^{p+(1-p) \pi}}$. Parameters $\{B, p, \pi, \gamma\}$ are such that $B \leq \bar{B}$, where $\bar{B}$ is given by

$$
\bar{B}\left[\pi(1-\ln \bar{B})+\frac{1}{1-p} \ln Z\right]=\gamma
$$

Assumption 3. Parameters $\{p, \pi, \gamma\}$ are such that

$$
p \geq \frac{\pi(1-\gamma)}{\gamma(1-\pi)}
$$

Assumption 4. Parameters $\{B, p, \pi\}$ are such that

$$
B>\frac{1}{p+(1-p) \pi} \equiv \underline{B}
$$

While Assumption 2 ensures that the socially efficient situation is that which includes strategy $S_{Q}$ to be followed in state $L$, Assumption 3 is made to guarantee $K_{Q}^{F B} \geq K_{C}^{F B}$ and Assumption 4 to guarantee $K_{C}^{F B}>0$. Assumption 3 could be restated in the way that it requires the probability of success of the gamble on resurrection, $\pi$, to be sufficiently low (at most equal to $\frac{\gamma p}{1-(1-p) \gamma}$ ). 
Proof of $B_{1} \leq B_{2}$

The statement to be proved to hold is the following:

$$
B_{1}(p, \pi, \gamma, V)>B_{2}(p, \pi, \gamma, V) \Rightarrow B_{1}(p, \pi, \gamma, V) \text { violates Assumption } 2 .
$$

Suppose $B_{1}(p, \pi, \gamma, V)>B_{2}(p, \pi, \gamma, V)$. This means that

$\exists B$ such that $B<B_{1}(p, \pi, \gamma, V)$ and $B>B_{2}(p, \pi, \gamma, V)$.

$B>B_{2}(p, \pi, \gamma, V)$ is equivalent to having parameters $B, p, \pi, \gamma, V$ such that

$$
F\left(K_{Q}^{T}(p, \pi, \gamma, V), 0, S_{Q}\right)<F\left(K_{C}^{T}(p, \pi, \gamma, V), r_{C}^{T}, S_{Q}\right)
$$

According to Proposition $3, K_{C}^{T}=K_{C}^{F B}$. In addition, $B<B_{1}(p, \pi, \gamma, V)$ implies by Proposition 2 that $K_{Q}^{T}=K_{Q}^{F B}$. Thus we can rewrite the inequality to

$$
F\left(K_{Q}^{F B}(p, \pi, \gamma, V), 0, S_{Q}\right)<F\left(K_{C}^{F B}(p, \pi, \gamma, V), r_{C}^{T}, S_{Q}\right)
$$

That is

$$
\begin{array}{r}
V+p B \ln \left(K_{Q}^{F B}+1\right)+[(1-p) \gamma-1] K_{Q}^{F B}< \\
<[p+(1-p) \pi]\left[V+B \ln \left(K_{C}^{F B}+1\right)-\left(1+r_{C}^{T}\right) K_{C}^{F B}\right] .
\end{array}
$$

Using $[p+(1-p) \pi]\left(1+r_{C}^{T}\right) K_{C}^{F B}=K_{C}^{F B}-(1-p)(1-\pi) V$, which stems from the creditor's participation constraint (20) holding with equality, we can rearrange it to

$$
\begin{array}{r}
V+p B \ln \left(K_{Q}^{F B}+1\right)+[(1-p) \gamma-1] K_{Q}^{F B}< \\
<[p+(1-p) \pi] B \ln \left(K_{C}^{F B}+1\right)-K_{C}^{F B} .
\end{array}
$$


Thus, $B$ violates Assumption 2. As $B<B_{1}(p, \pi, \gamma, V)$, this means that also $B_{1}(p, \pi, \gamma, V)$ violates Assumption 2.

Q.E.D. 


\section{References}

Adler, B. E. 1992. "Bankruptcy and Risk Allocation." Cornell Law Review 77:439489.

Akerlof, George A., and Paul M. Romer. 1994, April. Looting: The Economic Underworld of Bankruptcy for Profit. NBER Working Paper No. 1869.

Baird, Douglas G. 2003, February. Enron and the Long Shadow of Stat. 13 Eliz. Nortwestern University School of Law and Economics Colloquium Series.

Baird, Douglas G., and Robert K. Rasmussen. 2002a. "The End of Bankruptcy." Stanford Law Review 55 (3): 751-90.

2002b. "Four (or Five) Easy Lessons From Enron." Vanderbilt Law Review, vol. 55 .

—. 2003. "Chapter 11 at Twilight." Stanford Law Review 56 (3): 673-700.

Bar-Gil, Oren, and Lucian Arye Bebchuk. 2003, June. Misreporting Corporate Performance. Harvard Law and Economics Discussion Paper No. 400.

Bebchuk, Lucian Arye. 1991. The Effects of Chapte 11 and Debt Renegotiation on Ex Ante Corporate Decisions. Harvard University, mimeo.

- 2001, August. Ex Ante Costs of Violating Absolute Priority in Bankruptcy. CEPR Discussion Paper No. 2914.

Bebchuk, Lucian Arye, and Randal C. Picker. 1993. Bankruptcy Rules, Managerial Entrenchment, and Firm-Specific Human Capital. University of Chicago Law School, John M. Olin Law and Economics Working Paper No. 16.

Berglof, Erik, Gérard Roland, and Ernst-Ludwig von Thadden. 2003, August. Optimal Debt Design and the Role of Bankruptcy. Université de Lausanne, Ecole des HEC, DEEP, Working Paper.

Berglof, Erik, and Ernst-Ludwig von Thadden. 1994. "Short-Term Versus Long-Term Interests: Capital Structure with Multiple Investors." The Quarterly Journal of Economics 109 (4): 1055-84.

Berkovitch, Elazar, and Ronen Israel. 1998, March. Optimal Bankruptcy Laws Across Different Economic Systems. William Davidson Institute at the University of Michigan Business School, Working Paper.

Berkovitch, Elazar, Ronen Israel, and Jaime F. Zender. 1998. "The Design of Bankruptcy Law: A Case for Management Bias in Bankruptcy Reorganizations." Journal of Financial and Quantitative Analysis 33, no. 4 (December).

Bester, Helmut. 1994. "The Role of Collateral in a Model of Debt Renegotiation." Journal of Money, Credit and Banking 26 (1): 72-86.

Betker, Brian L. 1995. "Management's Incentives, Equity's Bargaining Power, and Deviations from Absolute Priority in Chapter 11 Bankruptcies." Journal of Business 68 (2): 161-83. 
Biais, Bruno, and Gilles Recasens. 2002, September. Corrupt judges, credit rationing and the political economy of bankruptcy laws. Bank of England, Conference Proceedings, September 2002.

Bolton, Patrick, and David S Scharfstein. 1996. "Optimal Debt Structure and the Number of Creditors." Journal of Political Economy 104 (1): 1-25.

Carapeto, Maria. 2000, September. Is Bargaining in Chapter 11 Costly? City University Business School, Working Paper.

Daigle, K. H., and M. T. Maloney. 1990. Residual Claims in Bankruptcy. Clemson University Working Paper.

Decamps, Jean-Paul, and Antoine Faure-Grimaud. 2002. "Excessive continuation and dynamic agency costs of debt." European Economic Review 46:1623 - 1644.

Eberhart, Allan C, William T Moore, and Rodney L Roenfeldt. 1990. "Security Pricing and Deviations from the Absolute Priority Rule in Bankruptcy Proceedings." Journal of Finance 45 (5): 1457-69.

Franks, J. R., and W. N. Torous. 1989. "An Empirical Investigation of U.S. Firms in Reorganization." The Journal of Finance 44 (3): 747-67.

- 1994. "A Comparison of Financial Recontracting in Distressed Exchanges and Chapter 11 Reorganizations." Journal of Financial Ecnomics 35 (3): 349-70.

Gertner, R., and R. C. Picker. 1992. Bankruptcy and the Allocation of Control. University of Chicago Law School, Working Paper.

Gertner, Robert, and David Scharfstein. 1991. "A Theory of Workouts and the Effects of Reorganization Law." Journal of Finance 46 (4): 1189-1222.

Harris, M., and A. Raviv. 1992. The Design of Bankruptcy Procedures. University of Chicago Law School, Working Paper.

Hart, Oliver. 2000. Different Approaches to Bankruptcy. NBER Working Paper No. 7921.

Hart, Oliver, and John Moore. 1998. "Default and Renegotiation." The Quarterly Journal of Economics 113 (1): 1-44.

Knot, Ondrej, and Ondrej Vychodil. 2005. "What Drives the Optimal Bankruptcy Law Design?" Czech Journal of Economics and Finance (Finance a uver) 55 (3-4): $110-123$.

Lambert-Mogiliansky, A., C. Sonin, and E. Zhuravskaya. 2003. Capture of Bankruptcy: A Theory and Evidence from Russia. Center for Economic and Financial Research in Moscow, Working Paper.

Longhofer, Stanley D., and Charles T. Carlstrom. 1995. "Absolute priority rule violations in bankruptcy." Economic Review, no. Q IV:21-30. available at http://ideas.repec.org/a/fip/fedcer/y1995iqivp21-30.html. 
LoPucki, L. M., and W. C. Whitford. 1990. "Bargaining over Equity's Share in the Bankruptcy Reorganization of Large, Publicly Held Companies." University of Pennsylvania Law Review, no. 139:125-196.

Picker, R. C. 1992. "Voluntary Petitions and the Creditors' Bargain." University of Cinicinati Law Review 61, no. 519.

Povel, Paul. 1999. "Optimal "Soft" or "Tough" Bankruptcy Procedures." Journal of Law, Economics and Organization 15 (3): 659-84.

Schwartz, Alan. 1998. "A Contract Theory Approach to Corporate Bankruptcy." The Yale Law Journal 107 (6): 1807-51.

- 2002, April. The Law and Economics Approach to Corporate Bankruptcy. Global Corporate Governance Forum Research Network Meeting - April 5, 2002.

Weiss, Lawrence A. 1990. "Bankruptcy resolution: Direct costs and violation of priority of claims." Journal of Financial Economics 27 (2): 285-314.

Weiss, Lawrence A., and Karen H. Wruck. 1998. "Information Problems, Conflicts of Interest and Asset Stripping: Chapter 11's Failure in the Case of Eastern Airlines." Journal of Financial Economics 48 (1): 55-97 (April).

White, Michelle J. 1998. Corporate Bankruptcy. in: Newman, P. K. (ed.): The New Palgrave Dictionary of Economics and the Law, London: Macmillan Press 1998.

2. 2005, August. Economic Analysis of Corporate and Personal Bankruptcy and Law. NBER Working Paper No. 11536. 
Individual researchers, as well as the on-line and printed versions of the CERGE-EI Working Papers (including their dissemination) were supported from the following institutional grants:

- Center of Advanced Political Economy Research [Centrum pro pokročilá politicko-ekonomická studia], No. LC542, (2005-2009),

- Economic Aspects of EU and EMU Entry [Ekonomické aspekty vstupu do Evropské unie a Evropské měnové unie], No. AVOZ70850503, (2005-2010);

- Economic Impact of European Integration on the Czech Republic [Ekonomické dopady evropské integrace na ČR], No. MSM0021620846, (2005-2011);

Specific research support and/or other grants the researchers/publications benefited from are acknowledged at the beginning of the Paper.

(c) Ondřej Knot, Ondřej Vychodil, 2006

All rights reserved. No part of this publication may be reproduced, stored in a retrieval system or transmitted in any form or by any means, electronic, mechanical or photocopying, recording, or otherwise without the prior permission of the publisher.

Published by

Charles University in Prague, Center for Economic Research and Graduate Education (CERGE) and

Economics Institute (EI), Academy of Sciences of the Czech Republic

CERGE-El, Politických vězñů 7, 11121 Prague 1, tel.: +420 224005 153, Czech Republic.

Printed by CERGE-EI, Prague

Subscription: CERGE-EI homepage: http://www.cerge-ei.cz

Editors: Directors of CERGE and EI

Managing editors: Deputy Directors for Research of CERGE and EI

ISSN 1211-3298

ISBN 80-7343-085-1 (Univerzita Karlova v Praze, CERGE)

ISBN 80-7344-074-1 (Národohospodářský ústav AV ČR, Praha) 
CERGE-EI

P.O.BOX 882

Politických vězňů 7

11121 Praha 1

Czech Republic http://www.cerge-ei.cz 